\title{
The radical induced cell death protein 1 (RCD1) supports transcriptional activation of genes for chloroplast antioxidant enzymes
}

\author{
Heiko Hiltscher ${ }^{1}$, Radoslaw Rudnik ${ }^{2}$, Jehad Shaikhali,4, Isabelle Heiber ${ }^{3}$, Marina Mellenthin ${ }^{1}$, \\ Iuri Meirelles Duarte ${ }^{1}$, Günter Schuster ${ }^{1}$, Uwe Kahmann ${ }^{5}$ and Margarete Baier ${ }^{1,2,3 *}$ \\ 1 Plant Science, Heinrich-Heine-University Düsseldorf, Düsseldorf, Germany \\ 2 Plant Physiology, Freie Universität Berlin, Berlin, Germany \\ ${ }^{3}$ Plant Biochemistry and Physiology, Bielefeld University, Bielefeld, Germany \\ ${ }^{4}$ Department of Forest Genetics and Plant Physiology, Umea Plant Science Center, Swedish University of Agricultural Sciences, Umea, Sweden \\ ${ }^{5}$ Molecular Cell Physiology, Bielefeld University, Bielefeld, Germany
}

\section{Edited by:}

Hanjo A. Hellmann, Washington

State University, USA

\section{Reviewed by:}

Hanjo A. Hellmann, Washington

State University, USA

Helmut Kirchhoff, Washington State University, USA

Elena A. Vidal, Pontificia Universidad

Catolica de Chile, Chile

\section{*Correspondence:}

Margarete Baier, Plant Physiology,

Freie Universität Berlin,

Königin-Luise-Straße 12-16,

14195 Berlin, Germany

e-mail:margarete.baier@fu-berlin.de
The rimb1 (redox imbalanced 1) mutation was mapped to the RCD1 locus (radical-induced cell death 1; At1g32230) demonstrating that a major factor involved in redox-regulation genes for chloroplast antioxidant enzymes and protection against photooxidative stress, RIMB1, is identical to the regulator of disease response reactions and cell death, RCD1. Discovering this link let to our investigation of its regulatory mechanism. We show in yeast that RCD1 can physically interact with the transcription factor Rap2.4a which provides redox-sensitivity to nuclear expression of genes for chloroplast antioxidant enzymes. In the rimb1 (rcd1-6) mutant, a single nucleotide exchange results in a truncated RCD1 protein lacking the transcription factor binding site. Protein-protein interaction between full-length $\mathrm{RCD} 1$ and Rap2.4a is supported by $\mathrm{H}_{2} \mathrm{O}_{2}$, but not sensitive to the antioxidants dithiotreitol and ascorbate. In combination with transcript abundance analysis in Arabidopsis, it is concluded that RCD1 stabilizes the Rap2.4-dependent redox-regulation of the genes encoding chloroplast antioxidant enzymes in a widely redox-independent manner. Over the years, rcd1-mutant alleles have been described to develop symptoms like chlorosis, lesions along the leaf rims and in the mesophyll and (secondary) induction of extra- and intra-plastidic antioxidant defense mechanisms. All these rcd1 mutant characteristics were observed in rcd1-6 to succeed low activation of the chloroplast antioxidant system and glutathione biosynthesis. We conclude that RCD1 protects plant cells from running into reactive oxygen species (ROS)-triggered programs, such as cell death and activation of pathogen-responsive genes (PR genes) and extra-plastidic antioxidant enzymes, by supporting the induction of the chloroplast antioxidant system.

Keywords: antioxidant system, Arabidopsis, chloroplast, RCD1, ROS

\section{INTRODUCTION}

Photosynthesis is accompanied by generation of reactive oxygen species (ROS) which impact on cellular metabolism and trigger signaling cascades (Baier and Dietz, 1999; Samuilov et al., 2002; Bechtold et al., 2008). The chloroplast antioxidant system protects chloroplasts against the destructive potential of ROS (Foyer et al., 1994) and controls spreading of ROS-signals (Zapata et al., 2005). Expression of chloroplast antioxidant enzymes responds

Abbreviations: $\mathrm{APx}$, ascorbate peroxidase; 2-CP, 2-Cys peroxiredoxin; 2CPA, 2-Cys peroxiredoxin A gene; aa: amino acid; AP2, apetala-2; 3AT, 3-amino1,2,4-triazol; BAC, Bacterial artificial chromosome; CAPS, cleaved amplified polymorphic sequences; Col-0, Arabidopsis thaliana var. Columbia-0; Csd, CuZn superoxide dismutase; DTT, dithiothreitol; F2/F3, filial generation 2/3; HR, hypersensitive response; Ler, Arabidopsis thaliana var. Landsberg erecta; PCD, programmed cell death; $r c d 1 / R C D 1$, (gene encoding) Radical-induced cell death 1; rimb1, redox-imbalanced 1; ROS, reactive oxygen species; sAPx, stromal ascorbate peroxidase; SRO1, similar to RCD1; SSLP, single sequence length polymorphism; tAPx, thylakoid-bound ascorbate peroxidase; X-Gal, 5-Brom-4-chlor-3-indoxyl- $\beta$ D-galactopyranosid. dynamically to stressful conditions (Baier et al., 2000, 2004; Kangasjärvi et al., 2008). The signal transduction pathways which adjust it to the chloroplast demands are under investigation.

Most detailed studies on the expressional regulation of the enzymatic components of the chloroplast antioxidant system have been performed for the 2-Cys peroxiredoxin A gene (2CPA) of Arabidopsis thaliana (Baier et al., 2004; Shaikhali et al., 2008; Shaikhali and Baier, 2010). Peroxiredoxins are an ancient type of peroxidases which detoxify $\mathrm{H}_{2} \mathrm{O}_{2}$ and alkyl hydroperoxides in a thiol-disulfide mechanism (Wood et al., 2003). Regeneration takes place by small thiol proteins, such as thioredoxins and glutaredoxins. 2CPA transcription activity correlates with the electron pressure at the acceptor site of photosystem-I (Baier et al., 2004), which reflects photosynthetic electron transport intensity relative to acceptor regeneration. Like the other chloroplast antioxidant enzymes, it is nuclear encoded. Transcriptional regulation responds to chloroplast signals (Baier et al., 2004). The signal transduction cascade is independent from the redox state 
of the plastoquinone pool, ROS and protochlorophyllide signaling, which regulate genes encoding proteins directly involved in photosynthetic electron transport or carbon assimilation, such as Cab, RbcS and PetE (Pfannschmidt, 2003), and genes for extra-plastidic antioxidant enzymes (Rossel et al., 2007).

The AP2-type transcription factor Rap2.4a was the first identified component of the signal transduction pathway regulating 2CPA transcription (Shaikhali et al., 2008): Upon slight redox-imbalances Rap2.4a dimerizes. In its dimeric state, it binds the redox box in the 2CPA promoter and activates $2 C P A$ transcription. In response to stronger oxidation, it oligomerizes and loses its activation potential on the 2CPA promoter. Besides 2CPA, Rap2.4a also orchestrates activation of various other genes encoding chloroplast antioxidant enzymes, such as stromal ascorbate peroxidase $(s A P x)$ and copper/zinc superoxide dismutase (Csd2) (Shaikhali et al., 2008). In absence of Rap2.4a, Arabidopsis thaliana develops photooxidative stress symptoms, such as chlorosis (Shaikhali et al., 2008).

To identify further elements involved in transcriptional regulation of genes for chloroplast antioxidant enzymes, a screen for redox-imbalanced mutants, the rimb-mutants, was set up in Arabidopsis thaliana (Heiber et al., 2007). A reporter gene line expressing luciferase under control of the 2CPA promoter was mutagenized with ethyl methansulfonate and mutants were selected in which the 2CPA promoter is less activated at the seedling state than in wildtype plants. Only lines were further propagated which were phenotypically indistinguishable from wildtype plants at seedling age.

In the mutant rimb1, 2CPA transcription levels are strongest decreased. Also stromal ascorbate peroxidase $(s A P x)$, thylakoid ascorbate peroxidase $(t A P x), \mathrm{CuZn}$-superoxide dismutase $(C s d 2)$, peroxiredoxin II E (PrxIIE), $\gamma$-glutamyl cysteine synthase $(\gamma E C S)$ and monodehydroascorbate reductase (MDHAR) transcript levels are lower than in the non-mutagenized parental line T192. Glutathione, ascorbate and chloroplast proteins are more oxidized in the mutant and glutathione biosynthesis is low. Consistent with insufficient chloroplast antioxidant protection, genes for extra-plastidic antioxidant defense enzymes are activated and the mutant develops stress symptoms, such as chlorosis, necrosis and early leaf senescence in the rosette state (Heiber et al., 2007). We concluded that RIMB1 is a major regulator controlling nuclear expression of various chloroplast antioxidant enzymes.

Here, we identified the nature of RIMB1 by map-based cloning. Mapping it to the rcdl-locus, which was previously described to protect plants from running into radical induced cell death (Overmyer et al., 2005), protecting from stress-induced senescence (Vainonen et al., 2012) and induction of disease response reactions (Zhu et al., 2013), combined so far independent lines of signal transduction analysis and showed that activation of the chloroplast antioxidant system protects plants from redox-imbalances and running into destructive and cost-intensive ROS-signaling cascades.

\section{MATERIALS AND METHODS PLANT MATERIAL AND GROWTH CONDITIONS}

The reporter gene line T19-2, which expresses luciferase under control of the 2CPA promoter (Baier et al., 2004), and the rimb1 mutant (Heiber et al., 2007) were taken from our own seed collection. All other T-DNA-insertion lines were retrieved from the Nottingham Arabidopsis Stock Centre or INRA Versailles. All external lines were tested by PCR for the T-DNA insertion site and homozygosis of the T-DNA insertion with T-DNA-flanking primers according to standard PCR protocols.

The plants were grown on soil as described previously (Heiber et al., 2007; Juszczak et al., 2012). Aseptic growth on plates was performed as described in Baier et al. (2004). Our standard conditions in the growth chambers were: $10 \mathrm{~h}$ light $(80-100 \mu \mathrm{mol}$ quanta $\left.\mathrm{m}^{-2} \mathrm{~s}^{-1}\right)$ at $20^{\circ} \mathrm{C}$ and $14 \mathrm{~h}$ darkness at $18^{\circ} \mathrm{C}$ and all day between 50 and $60 \%$ humidity. In the greenhouses the conditions were more variable as described in Suppl. 1.

For paraquat treatment, 2 week old aseptically grown plants were sprayed with $1.5 \mu \mathrm{M}$ paraquat. Seven days later, the survival rates were determined by comparison of the number of vital/green plants with the number of total plants.

\section{LUCIFERASE ACTIVITY MEASUREMENTS AND MAPPING}

Plant populations were scored for luciferase activity levels as reported in Heiber et al. (2007). Mapping was performed with SSLP and CAPS markers and DNA isolated according to standard procedures (Jander et al., 2002). Fragments of 180-300 bp were amplified, (in case of CAPS markers digested) and separated on $4 \%(\mathrm{w} / \mathrm{v})$ TAE-agarose gels containing ethidium bromide and analyzed fluormetrically according to standard procedures.

The Rcdl gene was amplified from genomic DNA with gene specific primers by PCR using a proof-reading polymerase. The amplificates were cloned into pJET1.2 (Fermentas, St.Leon-Rot, Germany) following blunting of the DNA ends. The plasmids were transformed in OneShot TOPO cells for amplification, re-isolated and purified with the Wizard Plus Minipreps DNA Purification System by Promega (Munich, Germany) and sequenced by GATC Biotech (Konstanz, Germany).

For allelism testing, the mutant was crossed to the nonmutagenized background line T19-2 (Heiber et al., 2007) and to rcd1-3. In crosses $\mathrm{A} \times \mathrm{B}$, the mother plant is named first (here: $\mathrm{A}$ ) and the name of the pollinator second (here: $\mathrm{B}$ ).

\section{RNA ISOLATION, cDNA SYNTHESIS, AND RT-PCR}

RNA isolation, cDNA synthesis and RT-PCR were performed according to Baier et al. (2000) with gene specific primers amplifying the $5^{\prime}$-end of the cDNAs (Suppl. 2) or with QuantPrimeoptimized primers (Arvidsson et al., 2008) spanning exon-intron borders (Suppl. 3) according to the MIQE standards, as described previously in Juszczak et al. (2012), using actin cDNAs as references.

\section{DETERMINATION OF HABITUS PARAMETERS}

Habitus parameters, such as root lengths and root branching, were determined after digital imaging using the software packages EZ-Rhizo (Armengaud et al., 2009) and ImageJ (Sheffield, 2007).

\section{LIGHT MICROSCOPY}

Cell size parameters and stomata densities were determined with fresh epidermis stripes using a Zeiss Axio Imager Light 
microscope and the Axio vision (Zeiss, Jena, Germany) and ImageJ (Sheffield, 2007) software packages.

\section{ELECTRON MICROSCOPY}

For scanning electron microscopy, freshly cut leaf sections were transferred to brazen specimen holders and gold-sputter coated for $180 \mathrm{~s}$ at $35 \mathrm{~mA}$ using a Agar Sputter Coater (Agar Scientific Ltd., UK) and analyzed by scanning electron microscopy [SEM; LEO 1430 (VP), LEO Ltd., Germany] at $20-21 \mathrm{kV}$ and a working distance of $30 \mathrm{~mm}$. Scaling was automatically performed using the intrinsic calibration mode. Transmission electron microscopy was performed as described in König et al. (2002).

\section{YEAST-2-HYBRID PROTEIN-PROTEIN INTERACTION TESTS}

The $r c d 1$ cDNAs were amplified from wildtype and mutant material using the primers AAAAAGAATTCATGGAAGCCAAGA TCGTC, and AAAACCCGGTTACAATCCACCTGCACC. The amplificates were cloned into the EcoRI/SmaI-sites of pGBT9 (Clontech Laboratories, Mountain View, USA) upstream of the HIS3 gene. The yeast strain Y187 was co-transformed with pGBT9-RCD1 and pACT2-clone1 (Shaikhali et al., 2008) encoding Rap2.4a. The transformants were grown for 6 days at $30^{\circ} \mathrm{C}$ on $\mathrm{SD}$ media lacking tryptophan and leucine (Ausubel et al., 2001). Positive interactions were tested in $\beta$ galactosidase colony-lift filter assays as described in Schneider et al. (1996).

Alternatively interactions were tested in the HF7c yeast strain co-transformed with pGBT9-RCD1 and pACT2-clone1 (Shaikhali et al., 2008) on SD media lacking histidine, tryptophan and leucine, and supplemented with $20 \mathrm{mM} 3$-amino-1,2,4triazole (3-AT).

For effector treatments, pGBT9-RCD1 + pACT2-clone1 double transformed $\mathrm{Y} 187$ cells were grown in liquid SD media lacking tryptophan and leucine. Aliquots were supplemented with $\mathrm{H}_{2} \mathrm{O}_{2}$, ascorbate and DTT. As positive control, commercially available pVA and pTD1 plasmids were co-transformed for co-expression of the strongly interacting proteins p53 and SV 40 large T-Antigen (Li et al., 1994).

\section{CHLOROPHYLL-A FLUORESCENCE ANALYSIS}

Chlorophyll-fluorescence was analyzed with a MINI-PAM fluorimeter (Walz, Effeltrich, Germany) after 30 min dark treatment. The maximum quantum yield $\left(\mathrm{F}_{\mathrm{V}} / \mathrm{F}_{\mathrm{M}}\right)$ was determined with a saturating light flash $\left(>2000 \mu \mathrm{mol}\right.$ quanta $\left.\mathrm{m}^{-2} \mathrm{~s}^{-1}\right)$. Afterwards the plants were illuminated for $5 \mathrm{~min}$ with actinic light $\left(180 \mu \mathrm{mol}\right.$ quanta $\left.\mathrm{m}^{-2} \mathrm{~s}^{-1}\right)$. The efficient quantum yield of photosystem II $\left(\mathrm{F}_{\mathrm{V}^{\prime}} / \mathrm{F}_{\mathrm{M}^{\prime}}\right)$ and photochemical quenching were determined every $20 \mathrm{~s}$ with a saturating light flash. Calculations were performed as described in Schreiber and Bilger (1993).

\section{STATISTICAL ANALYSIS}

Significance of difference was analyzed by Student's T-Test and the independence by $\mathrm{X}^{2}$-testing. For the latter, the results observed with the non-mutagenized background line T19-2 (Baier et al., 2004) were defined as expectation.

\section{RESULTS \\ PHENOTYPE-BASED SELECTION OF A rimb1-POSITIVE MAPPING POPULATION}

The rimb mutants were generated by mutagenizing the reporter gene line T19-2, which expresses luciferase under control of the 2CPA-promoter (Heiber et al., 2007). For mapping of the recessive mutant locus, the segregating F2 population of the cross of rimb1 to the Arabidopsis wildtype Landsberg erecta (Ler) was screened for low luciferase activity. Applying the same scoring procedure as previously used with segregating backcross populations (rimb1 × T19-2 and T19-2 × rimb1) (Heiber et al., 2007), almost twice the expected number of plants $(47.3 \%$ of the F2 seedlings, genotyped to be positive for the reporter gene construct by PCR) showed low luciferase activity.

To separate the rimb1 mutant locus from the interfering accession-specific locus, F2 lines with less than 60\% luciferase activity (relative to the parental line) were sub-classified into 4 groups according to their luciferase activity level. The F3progenies were grown side by side in the greenhouse and monitored for growth and color phenotypes. In three independently grown sub-populations of at least 200 plants with 25-30\% luciferase at an age of 10 days, between 50 and $83 \%$ of the plants developed chlorotic and necrotic lesions in the rosette state, as previously observed for rimb1 (Heiber et al., 2007). Later during development, necrosis, limited leaf blade growth and wrinkling of the leaf surface were observed. In contrast, chlorosis and abnormal leaf development were only observed in up to $6 \%$ of the plants in sub-populations with $>60 \%$ of luciferase activity (relative to the parental line T19-2) or in plants with less than $15 \%$ luciferase activity indicating linkage of the leaf phenotype and medium-low-luciferase phenotype.

\section{CO-SEGREGATION OF LOW-LUCIFERASE WITH ABNORMAL, CHLOROTIC LEAF DEVELOPMENT}

To proof that abnormal leaf development in the rosette stage co-segregates with low luciferase activity at seedling age, phenotypically normal (similar to T19-2; Figure 1B) and abnormal plants (similar to rimb1 ( $r c d 1-6)$; Figure 1B) were selected from a population of 300 soil-grown F2 plants of the cross of rimb1 and Ler (without pre-screening for luciferase activity). The F3 progeny of 20 plants with clearly abnormal leaves (chlorotic, serrated and/or necrotic) and 40 plants with clearly normally shaped and green leaves were screened for luciferase activity at 10 days, when the mutant seedlings were still visually indistinguishable from wildtype (Heiber et al., 2007). For all 20 lines with leaf defects in the F2 generation, the 2CPA-promoter-driven luciferase activity was decreased in 10 day old F3 seedlings.

From the lines, which showed a wildtype-like habitus in the F2 generation in the rosette state, in 31 lines the luciferase activity was not decreased in $\mathrm{F} 3$ generation. In the 9 lines with decreased luciferase activity of (by average) $56 \%$ of the F3 plants developed abnormally shaped leaves at an age of 6 weeks. In parallel grown plants of the non-mutagenized parental line T19-2, only up to $2 \%$ of the F3 plants developed chlorosis and necrosis at an age of 6-8 weeks. According to $\mathrm{X}^{2}$-testing, the numbers showed that low luciferase activity correlates with the phenotypical difference to the parental line (error probability: $<10^{-15}$ ). For all 

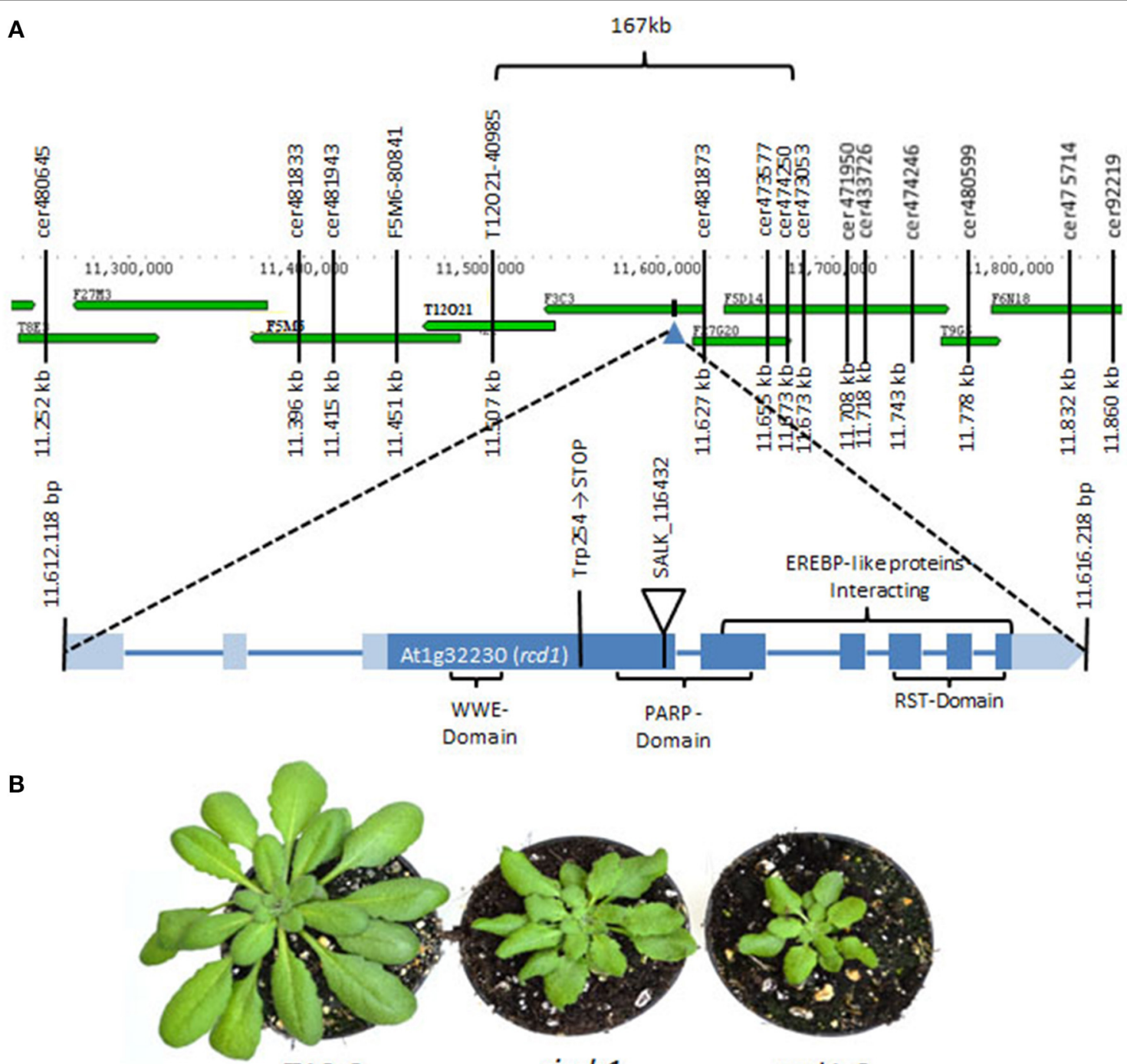

T19-2

rimb1
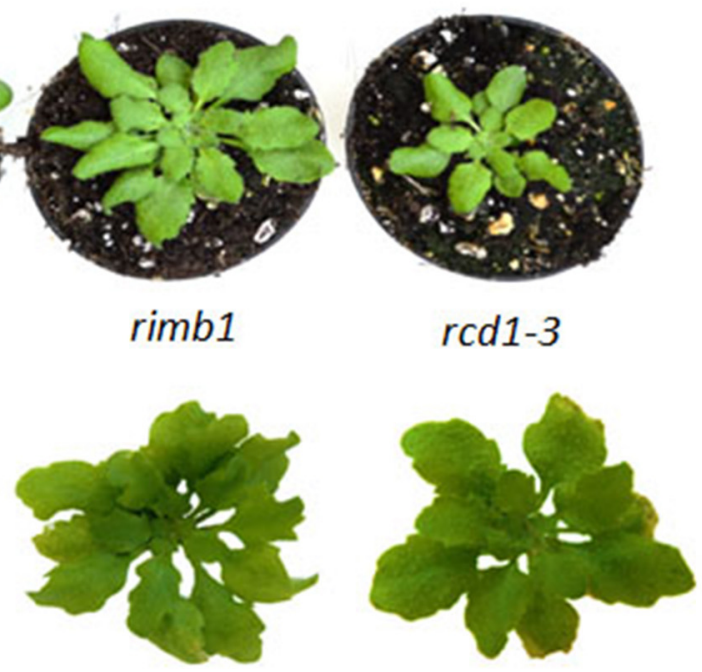

FIGURE 1 | Mapping of the rimb1 mutation. (A) The rimb1 mutation was mapped to a $167 \mathrm{~kb}$ region on chromosome 1 with SSLP and CAPS markers. Following analysis of the target region with T-DNA insertion mutants, the mutation ( $\mathrm{G} \rightarrow \mathrm{A}$ ) was identified in the Trp254 codon of gene At1g32230 by sequencing. (B) Top: Comparison of rimb1 mutants with the RCD1-deficient SALK-line_11643 (rcd1-3) (average phenotypes) after 6 weeks at short-day conditions. Bottom: The most severe leaf form phenotypes in parallel grown rimb1 and rcd1-3 populations.
20 abnormal lines the 2CPA-promoter-driven luciferase activity was decreased demonstrating co-segregation of a low luciferase activity level with the phenotype (error probability: $<10^{-40}$ ).

\section{MAPPING OF THE rimb1-MUTANT LOCUS}

Due to the correlation of abnormal leaf development with low luciferase activity, the rimb1-mapping population was extended by screening the F2 progeny of rimb1xLer for the leaf phenotype. 652 lines with lighter green and abnormally shaped leaves were selected. The mapping population was purified by excluding all lines, which had lost the luciferase construct in the F2 (according to PCR-based genotyping with primers binding the luciferasecDNA) and rescreened in the F3 for low luciferase activity. With 350 luciferase-positive lines the mutation was mapped with 
SSLP and CAPS markers to a $167 \mathrm{~kb}$ region on chromosome 1 (Figure 1A). The target region between the markers Cer474250 and $\mathrm{T} 12 \mathrm{O} 21$ was screened for candidate genes by comparing the habitus of T-DNA insertion lines with rimb1.

The homozygous offspring of SALK-Line_116432 ( $r c d 1-3)$ (Katiyar-Agarwal et al., 2006) was phenotypically similar to rimb1 (Figure 1B). $r c d 1-3$ carries a T-DNA insertion in gene At1g32230 encoding RADICAL INDUCED CELL DEATH-1 (RCD1) (Teotia and Lamb, 2009; Figure 1A).

rimb1 and $r c d 1-3$ showed lighter green and stronger serrated leaves under short day conditions in controlled environment $\left(10 \mathrm{~h} 100 \mu \mathrm{mol}\right.$ quanta $\mathrm{m}^{-2} \mathrm{~s}^{-1} ; 20^{\circ} \mathrm{C} ; 14 \mathrm{~h}$ dark at $18^{\circ} \mathrm{C}$ ) (Figures 1B, 2). Later in both lines, small rosettes with 3-5 leaves were formed at the knots along the inflorescence axis instead of cauline leaves in both lines (Figure 2B) indicating that rimb1 is allelic to $\operatorname{rcd} 1$ (Ahlfors et al., 2004).

\section{GENETIC ALLELISM TEST}

Allelism was tested by crossing the recessive rimb1 mutant (Heiber et al., 2007) to the rcd1-3 T-DNA insertion line and $r c d 1$ 3 to rimb1. In the F1 generation, 64 and $67 \%$ of the plants showed the rimb1- and rcd1-3-typical abnormal leaf habitus, while none

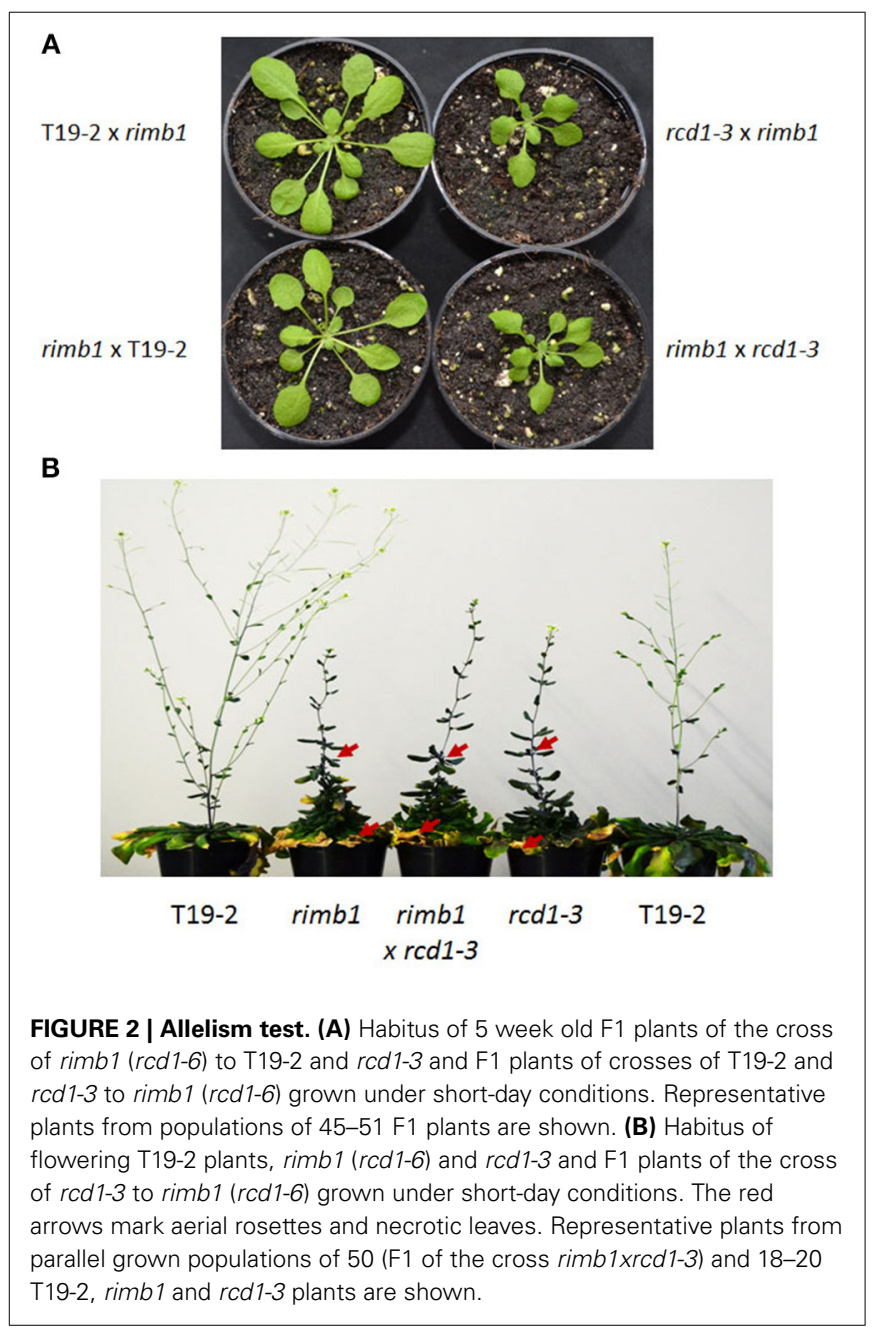

of the F1 progeny of crosses of rimb1 to T19-2 and T19-2 to rimb1 did (Figure 2). The number of phenotypically positive F1 plants of the crosses rimb1xrcd1-3 or $r c d 1-3 x$ rimb1 was in the range of the penetrance of the phenotype in parallel grown homozygous rimb1 and $r c d 1-3$ plants (60 and 78\%) and the average phenotype variations (Suppl. 1) demonstrating that rimb1 is an $r c d 1$ allele and, therefore, that the low activation of genes for chloroplast antioxidant enzymes (Heiber et al., 2007) results from a defect in the same gene, which protect Arabidopsis from running into cell death (Overmyer et al., 2005).

\section{SEQUENCING-BASED IDENTIFICATION OF THE MUTATION}

For the final proof of identity, the $r c d 1$ gene was amplified by PCR from genomic DNA of rimb1 and the parental line T19-2. The PCR products were cloned, sequenced and compared. In the rcd1-DNA sequence of rimb1, but not in that of T19-2, a single base pair exchange was observed. Exchange of $\mathrm{G}$ into A modified the Trp-codon (TGG) at position 254 into a stop codon (TAG) (Figure 1A). Rimb1 is an $r c d 1$ allele and was, therefore, renamed as $r c d 1-6$.

\section{ANALYSIS OF rimb1 FOR PHYSIOLOGICAL AND MORPHOLOGICAL rcd1 CHARACTERISTICS}

To describe the $r c d 1-6$ allele and enable comparison with other $r c d 1$-mutants, $r c d 1-6$ was tested for well-described $r c d 1$ phenotypes. Rcd1 mutants were characterized for their decreased sensitivity toward paraquat (Ahlfors et al., 2004; Fujibe et al., 2004). The same was observed for $r c d 1-6$ (Table 1). $r c d 1-6$ plants also showed decreased root lengths, but, by average, much milder as reported for $r c d 1-3$ by Teotia and Lamb (2011). The number of lateral roots was also only slightly increased (Figure 3A right). In highly variable populations, some of the $r c d 1-6$ mutants showed as strong phenotypes as Teotia and Lamb (2011) reported (Figure 3A left), while T19-2 plants did not.

Rcd1-6 plants formed by average less than $40 \%$ of the flowers wildtype Arabidopsis does (Figure 2). The rosette leaves were rougher (Figure 3B). The number of stomata per $\mathrm{mm}^{2}$ was with $12.1 \pm 5.3$ on the upper and $15.56 \pm 2.28$ on the lower surface decreased compared to T19-2 (20.2 \pm 5.6 and $17.6 \pm$ 3.1 , respectively). The outer cell surface of the upper epidermis is with $879.4 \mu \mathrm{m}^{2}$ slightly larger in $r c d 1-6$ (rimb1) than in T19-2.

The cell shape and surface texture was stronger affected in the lower epidermis. Clefts and tissue deformations were observed (Figure 3B) similar to the defects reported by Teotia and Lamb

Table 1 | Paraquat resistance of $r c d 1$ and T19-2 seedlings.

\begin{tabular}{lccc}
\hline & T19-2 & rimb1 (rcd1-6) & rcd1-3 \\
\hline Lethal plants & 211 & 72 & 41 \\
Vital plants & 6 & 214 & 116 \\
Number of plants & 217 & 286 & 157 \\
Survival rate [\%] & 2.8 & 74.8 & 73.9 \\
\hline
\end{tabular}

Dead (pale) and vital (green) plants were counted 5 days after spraying of 2 week old plants with $1.5 \mu \mathrm{M}$ paraquat. 


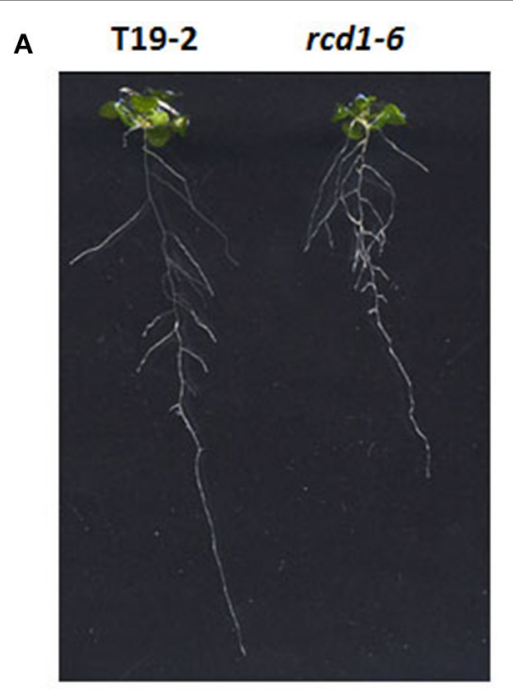

B
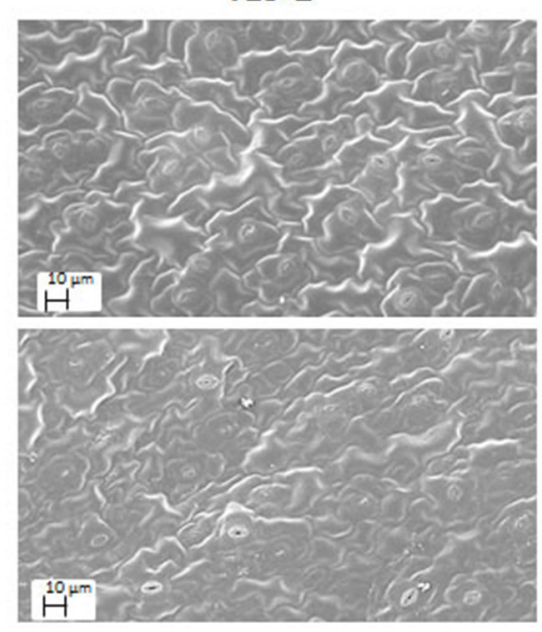

FIGURE 3 | (A) Root length and root branching in rcd1-6 (rimb1) and the parental line T19-2. Quantitative data were calculated from 30 plants grown aseptically on $0.5 \times \mathrm{MS}$-medium supplemented with $0.5 \%(\mathrm{w} / \mathrm{v})$ sucrose. The root lengths and the branching intensity were quantified by analysis of digital images with EZ-Rhizo and ImageJ. The length

variations and the lateral root numbers were not significantly different as analyzed by Student's $T$-Test $(\alpha=0.1)$. The photo shows representative
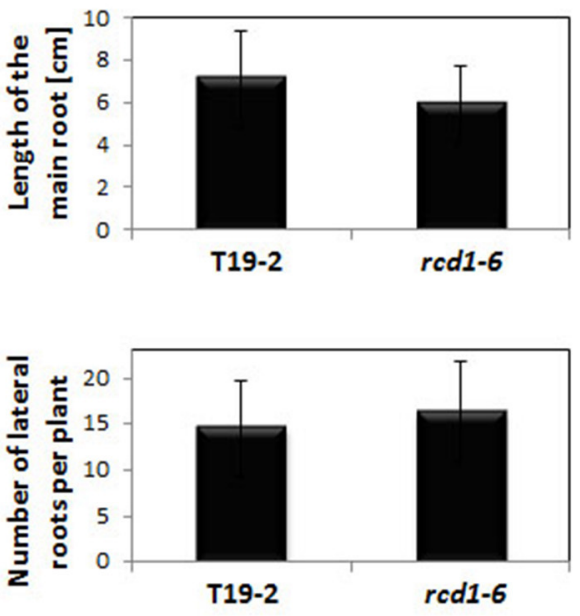

$\operatorname{rcd} 1-6$
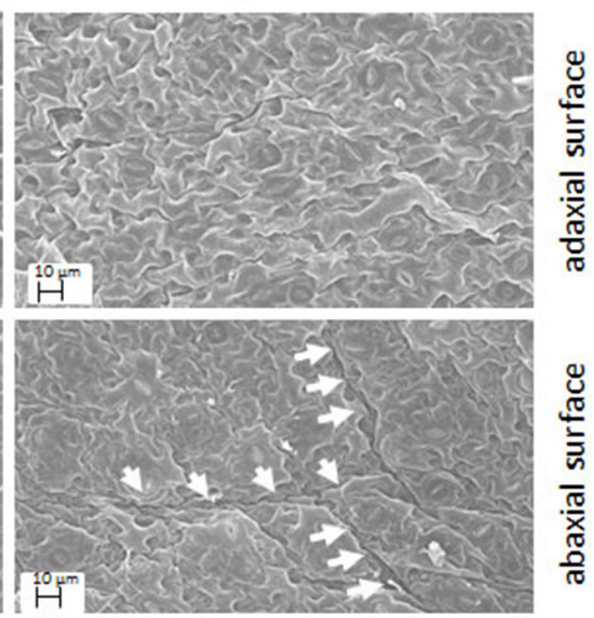

T19-2 and rcd1-6 plants of the analyzed populations. (B) Representative scanning electron images of the abaxial and adaxial the surfaces of full-grown leaves of rcd1-6 (rimb1) and the parental line T19-2 grown for 6 weeks in short day $\left(10 \mathrm{~h}\right.$ at $80-100 \mu \mathrm{mol}$ quanta $\mathrm{m}^{-2} \mathrm{~s}^{-1} / 14 \mathrm{~h}$ darkness) and a relative humidity of $50-60 \%$. Prior to microscopy the surfaces were sputtered with a thin layer of gold as described in material and methods. The arrows mark the rims of "clefts."
(2011) for $r c d 1-3$ demonstrating that in $r c d 1-6$ also groups of neighboring mesophyll cells run into cell death.

\section{RCD1 CAN BIND Rap2.4a}

The $r c d 1-6$ (rimb1) mutant has been isolated for decreased expression of 2CPA and other genes for chloroplast antioxidant enzymes at seedling stage (Heiber et al., 2007). The early effect on induction of the chloroplast antioxidant system poses the question how RCD1 is involved in the regulation of nuclear expression of the chloroplast antioxidant enzymes. Previous work (Belles-Boix et al., 2000; Ahlfors et al., 2004; Vainonen et al., 2012) suggested that RCD1 (previously designated CEO1) acts as a scaffold for various transcription factors in order to balance signal transduction cascades (Overmyer et al., 2000). Specificity is provided by distinct protein-protein interaction sites. The C-terminal RST-domain of RCD1 (Jaspers et al., 2010) selects target transcription factors by distinct recognition motifs (Vainonen et al., 2012).

Redox-regulation of 2CPA is mediated by the AP2-type transcription factor Rap2.4a (Shaikhali et al., 2008). To test whether RCD1 can interact with Rap2.4a under similar conditions (as used by Belles-Boix et al., 2000 to study RCD1-transcription factor interactions), a yeast-two-hybrid approach was chosen. It enables detection of protein-protein-interactions at low expression levels and quantification of the interaction strength in a complex protein environment of a living cell, but avoids problems, which are accompanied with e.g. pull-down assays, if the interaction of a multiple transcription factor binding protein as 
RCD1 (Belles-Boix et al., 2000; Jaspers et al., 2009, 2010) and a specific (weakly expressed) transcription factor should be studied.

The cDNA encoding RCD1 was cloned into the bait vector pGBT9 and the Rap2.4a cDNA into the prey vector pACT2. Double transformants of the yeast strain HF7c showed proteinprotein interaction by complementation of the histidine auxotrophy of the yeast strain. On $20 \mathrm{mM} 3$-AT, which increases the stringency by inhibiting histidine biosynthesis, the double transformant grew almost as good as the commonly used positive control, pVA-pTD1 double transformants (Figure 4 left) (Li et al., 1994). The pAct2-Rap2.4a-empty pGBT9 double transformants (negative control) did not grow.

Additional support for an interaction of Rap2.4a with RCD1 was given by $\beta$-galactosidase filter lift assays with double transformed yeast Y187 based on activation of a GAL4-promotorcontrolled LacZ reporter gene activation (Figure 4 right). The pGBT9-RCD1 and the pACT-Rap2.4a single transformants of Y187 (autoactivation test) showed no activation of the reporter gene (data not shown).

\section{THE PROTEIN-PROTEIN INTERACTION OF RCD1 AND Rap2.4a IS ONLY SLIGHTLY REDOX-REGULATED}

Rap2.4a confers redox-dependent modulation of quaternary structure (Shaikhali et al., 2008). It dimerizes upon slight oxidative shifts and oligomerizes upon severe stress conditions. These structural changes may affect the interaction with other proteins. To test whether the interaction of RCD1 and Rap2.4a is redox-regulated, the interaction specific $\beta$-galactosidase activity was used as a quantitative measure to compare the interaction strength. Double transformed yeast strains expressing a RCD1 bait construct (pGBT9-RCD1) and a Rap2.4a prey construct (pACT2-Rap2.4a) were treated with $0-1 \mathrm{mM}$ of the oxidant $\mathrm{H}_{2} \mathrm{O}_{2}, 0-10 \mathrm{mM}$ of the antioxidant ascorbate and $0-0.5 \mathrm{mM}$ of

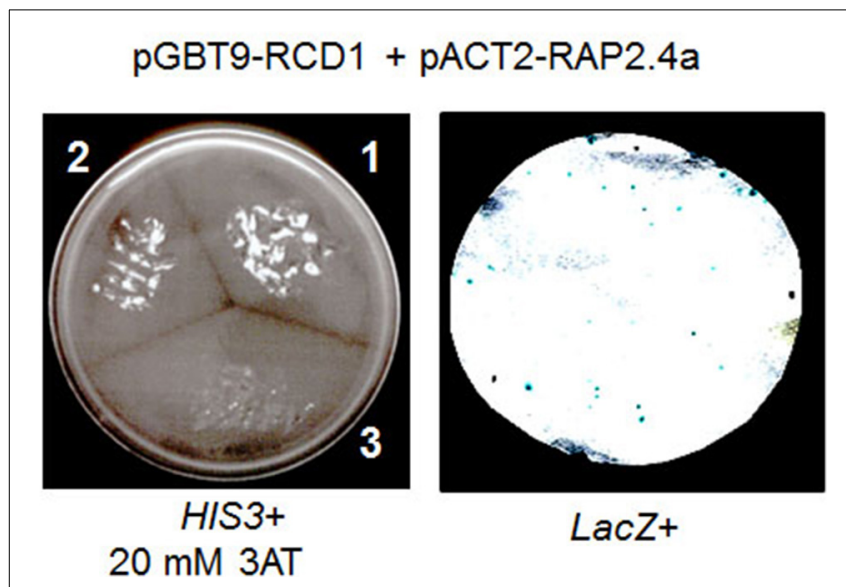

FIGURE 4 | RCD1-Rap2.4a interaction test in yeast. His3 activation by interaction of Rap2.4a with RCD1 (segment 2 in the left panel) is compared to the known interaction of pVA3 and pTD1 (segment 1 in the left panel) and a non-transformed control (segment 3 in the left panel). RCD1-Rap2.4 interaction-based activation of the GAL4 promoter was confirmed by monitoring LacZ reporter activation in pGBT9-RCD1 and pAct2-Rap2.4a double transformed yeast cells (right). the reducing disulphide DTT (Figure 5). While DTT and ascorbate did not affect the interaction, a slight increase in the Rap2.4aRCD1 interaction strength was observed with $\mathrm{H}_{2} \mathrm{O}_{2}$. No $\mathrm{H}_{2} \mathrm{O}_{2}$ response was observed for protein-protein interaction of VA3 and TD1 (encoding SV40 large T-antigen and GAL4-AD and murine p53 protein and GAL4-BD; Li and Fields, 1993) (Figure 5), which served as a negative control.

\section{REDOX-REGULATION OF RCD1 EXPRESSION}

2CPA expression is strongly reduced by ascorbate application (Horling et al., 2003; Baier et al., 2004; Figure 6). The ascorbatecontrolled transcriptional regulation is light-dependent and, as co-application of DCMU demonstrated, interwoven with the control of 2CPA expression by photosynthetic signals (Shaikhali and Baier, 2010). To test whether RCD1 is involved in the ascorbate response, 2CPA and $R C D 1$ expression was analyzed in $r c d 1-3$ lines and compared with wildtype and, for further inside into the signaling network with, Rap2.4a knock-out lines in 6 week old plants grown under short-day conditions (Figure 6).

Ascorbate increased the transcript level of $R c d 1$ in wildtype and Rap2.4a knockout lines (Figure 6). In response to ascorbate, 2CPA transcript levels only slightly changed in the RCD1 knock-out line $r c d 1-3$, while they decreased in wildtype plants and increased in Rap2.4 knock-out lines. The fact that the 2CPA transcript amount is much less regulated by ascorbate in absence of RCD1 and that the response is inverted in absence of Rap2.4a demonstrates that RCD1 and Rap2.4a are essential for suppression of 2CPA expression upon ascorbate application. However, unlike in Rap2.4a-dependent regulation (Shaikhali et al., 2008), there was no correlation between RCD1 expression and $2 C P A$ transcript amount (Figure 6).

\section{RCD1 IS AN AGE-DEPENDENT REGULATOR OF THE ANTIOXIDANT SYSTEM}

Previously, we showed that the mRNA abundances of $C s d 2, s A P x$, and $t A P x$ are decreased in young $r c d 1-6$ plants in parallel to $2 C P A$ transcript levels (Heiber et al., 2007). To test the developmental stability of the RCD1 effect, the transcript abundance of genes encoding chloroplast proteins was analyzed in T19-2, $r c d 1-3$, and in Rap2.4a knock-out lines in the rosette state.

At this stage, the 2CPA, Csd2, and sAPx transcript levels were slightly higher in the $r c d 1$-mutant than in wildtype plants (Figure 7), demonstrating that the RCD1 control on these genes is lost during rosette development (Figure 7). The transcript levels were still dependent on Rap2.4a availability (Figure 7).

The transcript levels of ApL3 (At4g39210; encoding the large subunit 3 of ADP glucose pyrophosphorylase) and the light harvesting complex protein Lhcb2.1 (At3g61470) were still significantly decreased in 6 week old mutants. Expression of ROSsensitive cytosolic ascorbate peroxidase 2 (APx2; At3g09640) and its inducing transcription factor ZAT10 (At1g27730) (Karpinski et al., 1997; Mittler et al., 2006) was increased in the RCDknock-out line (Figure 7), as reported before for $r c d 1-6$ seedlings (Heiber et al., 2007).

For more detailed analysis of the developmental regulation by RCD1, the transcript abundance regulation of RCD1, its closest homolog SRO1, 2CPA, and Rap2.4a was compared between 

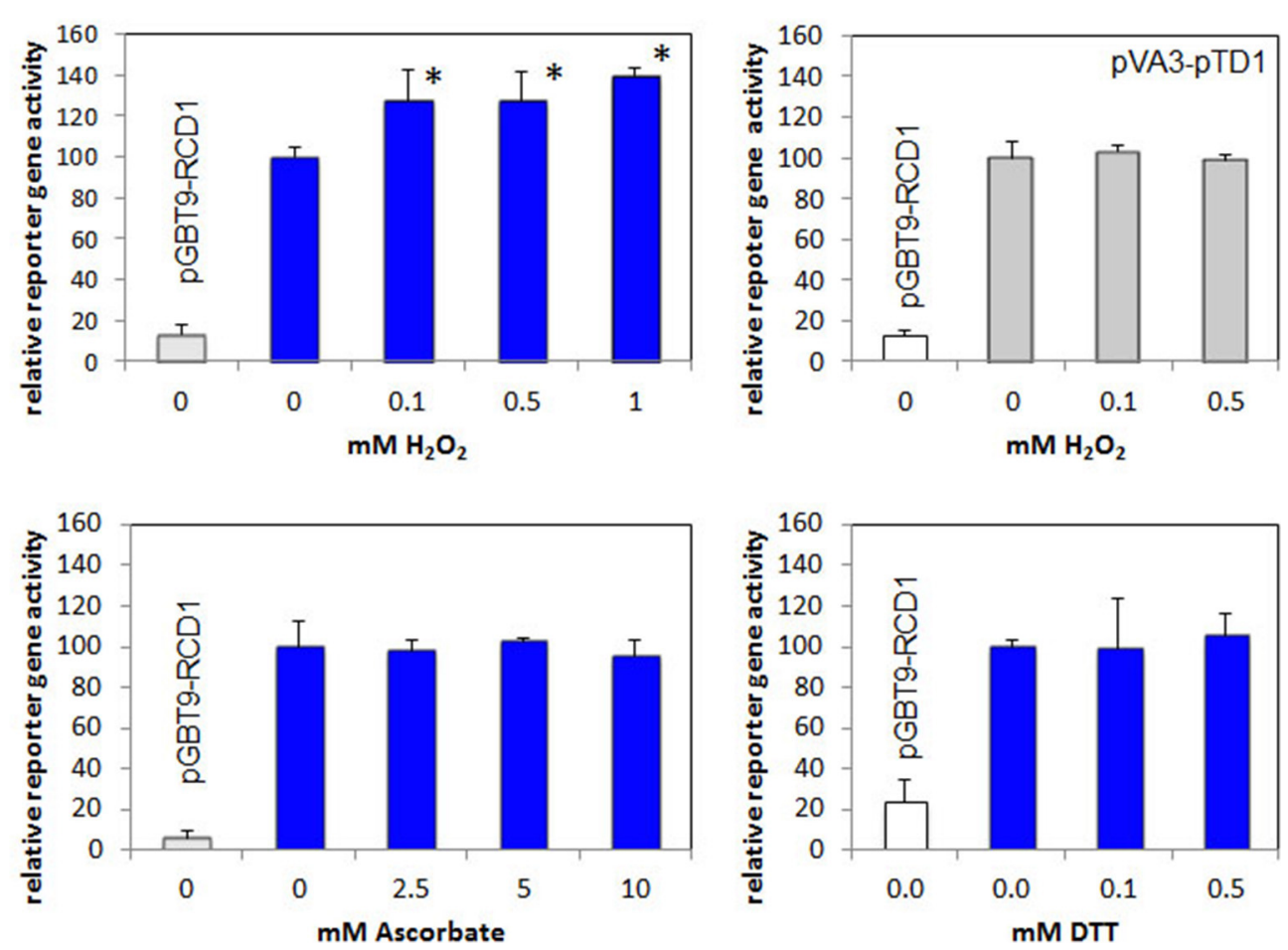

FIGURE 5 | Analysis of redox regulation of the RCD1-Rap2.4 interaction in yeast by $\mathrm{H}_{2} \mathrm{O}_{2}$, ascorbate and DTT compared to the $\mathbf{H}_{\mathbf{2}} \mathbf{O}_{\mathbf{2}}$-regulation of pVA3-pTD1. As a measure for the protein-protein interaction the Gal4-driven LacZ activity was quantified. In all experiments, yeast only transformed with the RCD1-expression construct pGBT-RCD1 served as a negative control. Significant differences to the untreated control (Student's T-Test; $\alpha=0.01 ; n=7$ ) are labeled with an asterisk.

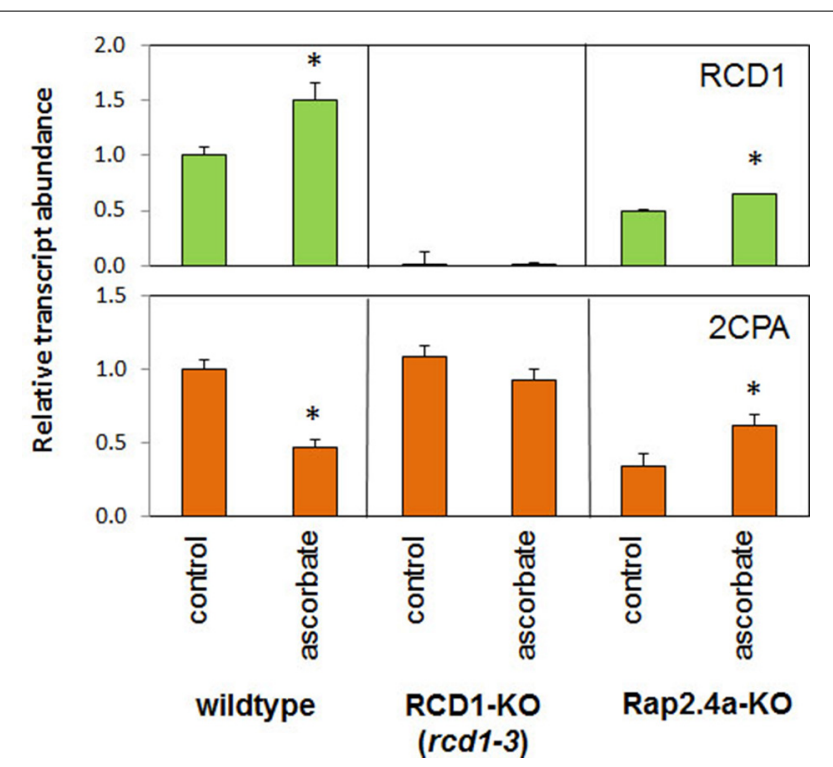

FIGURE 6 | Transcript abundances of 2CPA and RCD1 in 6 week old Arabidopsis wildtype plants and RCD1 and Rap2.4a knock-out lines standardized on actin transcript levels and normalized on the transcript level of the respective gene in wildtype plants under control conditions in response to ascorbate as determined by RT-PCR and gel electrophoresis. Significant differences to the untreated control (Student's $T$-Test; $\alpha=0.01 ; n=3$ ) are labeled with an asterisk.
2, 4, 5, and 6 week old plants (Figure 8). The 2-Cys peroxiredoxin transcript levels were slighter decreased in young $r c d 1-3$ and $r c d 1-6$ plants consistent with previous data (Heiber et al., 2007; Figure 7). From 5 weeks onwards, when leaf formation and leaf elongation stopped, 2CPA levels accumulated to higher levels in $r c d 1-3$ and $r c d 1-6$ than in the parental line T19-2 demonstrating that the RCD1 effect on 2CPA expression is age-dependent and lost in mature tissues.

$R C D 1$ transcripts were barely detectable in the T-DNA insertion line $r c d 1$-3 (Teotia and Lamb, 2009; Figures 6, 8). In contrast, rcd1-6, which has a single nucleotide exchange in the coding region of the RCD1 gene, accumulated RCD1-mRNA to a slightly higher level than wildtype plants (T19-2) at 2 and 4 weeks age. Transcript abundance of $S R O 1$, the closest homolog of $R C D 1$, is similar in $r c d 1-3$ and $r c d 1-6$ with slightly more SRO1 mRNA in $r c d 1-3$. Compared to T19-2, the SRO1 transcript levels were increased in both $r c d 1$ mutants in the first 5 weeks indicating a transient compensatory induction.

Surprisingly, the mutants $r c d 1-3$ and $r c d 1-6$ differed in the regulation of the Rap2.4a transcript amount. In $r c d 1-6$, Rap2.4a transcript levels were increased to more than $150 \%$ at $2-5$ weeks. In $r c d 1-3$ Rap2.4a transcript levels were decreased in plants older than 2 weeks, indicating an allele-specific effect.

\section{CHLOROPLAST ULTRASTRUCTURE}

In the youngest leaves of 5 week old $r c d 1-6$ (rimb1) plants, chloroplasts were not significantly different from chloroplasts of the 


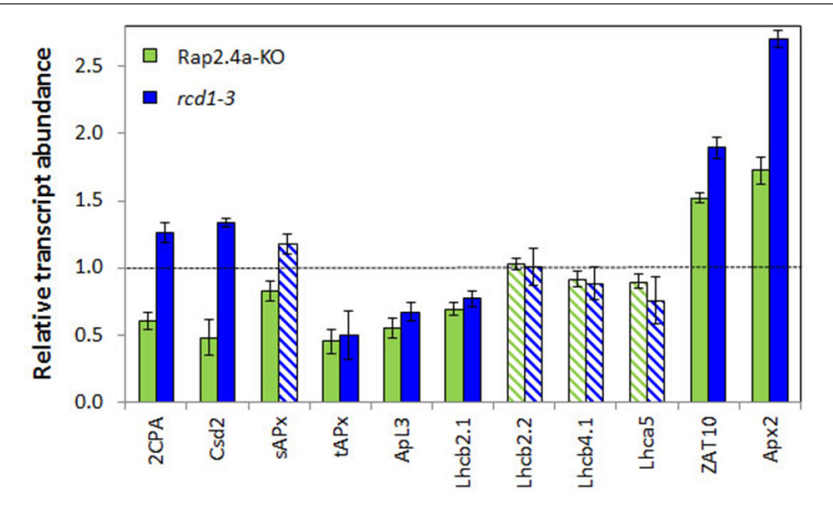

FIGURE 7 | Transcript levels of genes encoding chloroplast antioxidant enzymes (2CPA, Csd2, sAPx, and $t A P x)$, other nuclear encoded chloroplast proteins ( $A P L 3$ and $L H C s$ ) and the stress inducible transcription factor ZAT10 and its target gene Apx2 in 6 week old Rap2.4a- and rcd1-3 lines as determined by RT-PCR in actin standardized samples relative to wild-type plants. The experiment was performed with three biological replicates and two technical replicates per independently grown biological replicate. Significant differences to the untreated control (Student's $T$-Test; $\alpha=0.01 ; n=3$ ) are shown with filled bars, non-significant with striped bars.

parental line T19-2, which were exposed to the same conditions, with respect of grana number and grana stacking intensity (Figure 9). In $r c d 1-6$, starch granules were already observed at a very young developmental status, while the plastids were still dividing (Figure 9). Consistent with the slight chlorotic phenotype (Figures 1, 2; Heiber et al., 2007), the thylakoid stacking intensity was deceased to $2.36 \pm 0.62$ thylakoids in $r c d 1-6$ (rimb1) compared to $7.65 \pm 1.82$ thylakoids in T19-2 (Figure 9).

\section{CHLOROPHYLL-A FLUORESCENCE ANALYSIS}

Chlorophyll-a fluorescence analysis enables a non-destructive look on chloroplast function (Schreiber and Bilger, 1993). The quantum yield of photosystem II reflects photosynthetic electron transport efficiency and photochemical quenching the oxidation of the plastoquinone pool and, therefore, under most conditions, activation of the Calvin-Benson-Cycle. Although the maximum quantum yield of photosystem II $\left(\mathrm{F}_{\mathrm{V}} / \mathrm{F}_{\mathrm{M}}\right)$ (as determined immediately after 30 min dark relaxation) was similar in $r c d 1-6$ (rimb1) and T19-2 (Figure 10A), it increased slightly less in the light in the mutant. Between $45 \mathrm{~s}$ and 5 min of illumination, it was around $90 \%$ of that in T19-2 in rimb1.

Activation of photochemical quenching $(\mathrm{qP})$ was much slower in $r c d 1-6$ (rimb1) than in T19-2 for the first $90 \mathrm{~s}$ (Figure 10B). Ninety seconds after onset of light, it was only $62 \%$ that of T19-2 demonstrating problems with regulation of electron transfer within the photosynthetic electron transport chain or downstream.

\section{DISCUSSION}

\section{RCD1 REGULATES CHLOROPLAST ANTIOXIDANT PROTECTION}

The rcd1-6 (rimb1) mutant was isolated for decreased transcriptional activity of the plant 2-Cys peroxiredoxin gene 2CPA and decreased expression of other genes for chloroplast antioxidant

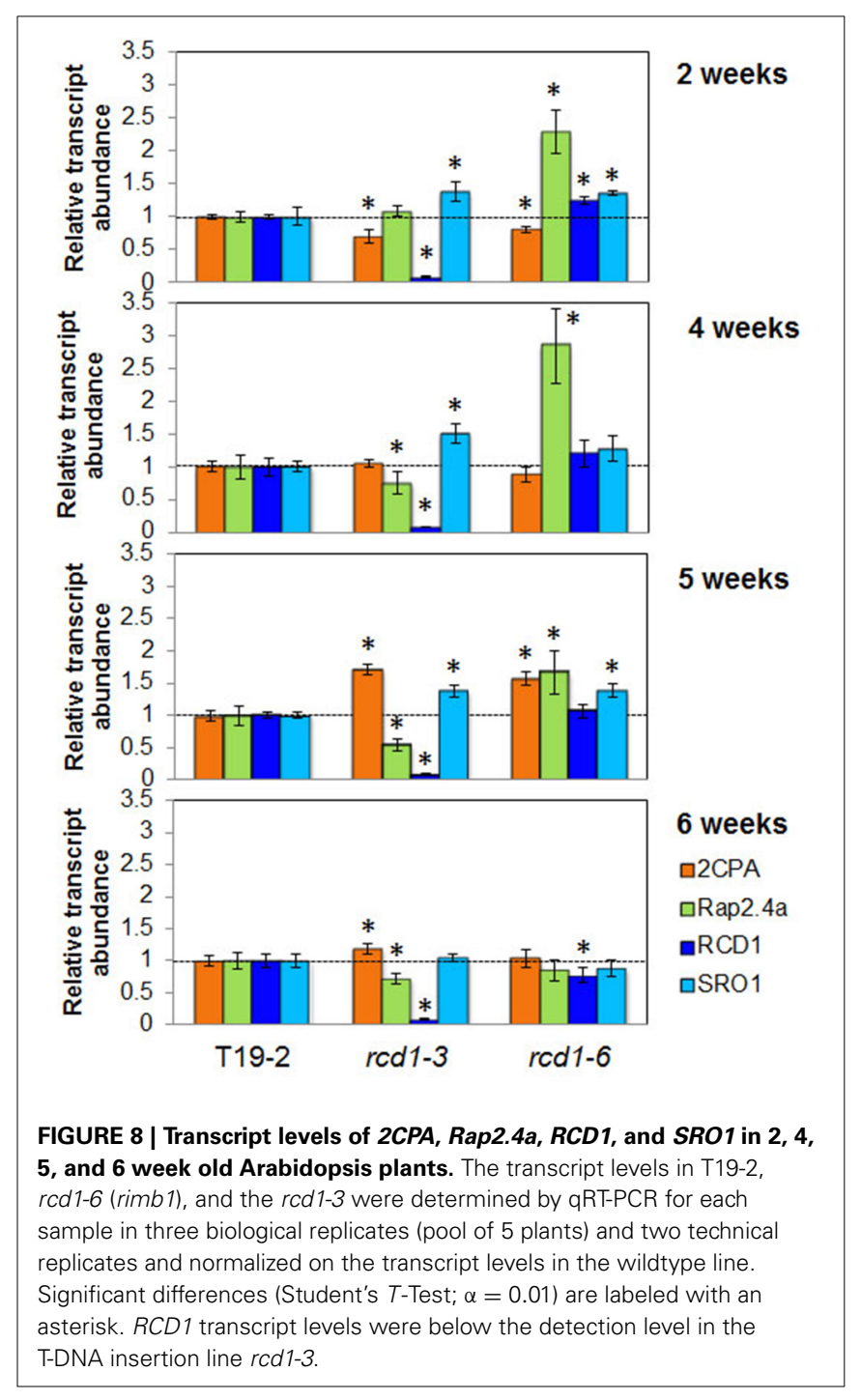

enzymes (Heiber et al., 2007). The exchange of the codon for Trp-254 (TGG) into a stop codon (TAG) results in translation termination within the PARP-domain and before the RST-domain of the encoded protein in $r c d 1-6$ (Figure 1A). The C-terminal RSTdomain is essential for interaction of RCD1 with transcription factors (Jaspers et al., 2009, 2010). RCD1 interacts with Rap2.4a in the complex protein environment of yeast cells (Figure 4), which regulates expression of various chloroplast antioxidant enzymes (Shaikhali et al., 2008).

RCD1 was first isolated in a screening approach aiming at the identification of plant homologs to the redox-regulated yeast transcription factor YAP1 (Belles-Boix et al., 2000). In yeast, YAP1 controls the expression of the oxidative stress regulon, including 2-Cys peroxiredoxin regulation (Lee et al., 1999). Lack of YAP1 function was complemented by RCD1 (Belles-Boix et al., 2000) due to its ability to form a scaffold for assembly of transcription factors (Jaspers et al., 2010). Mapping of rimb1 to the RCD1 locus demonstrates that RCD1 promotes expression of the orthologous gene and therefore, conservation of (at least part of the) redox control pathways from yeast to plants. 


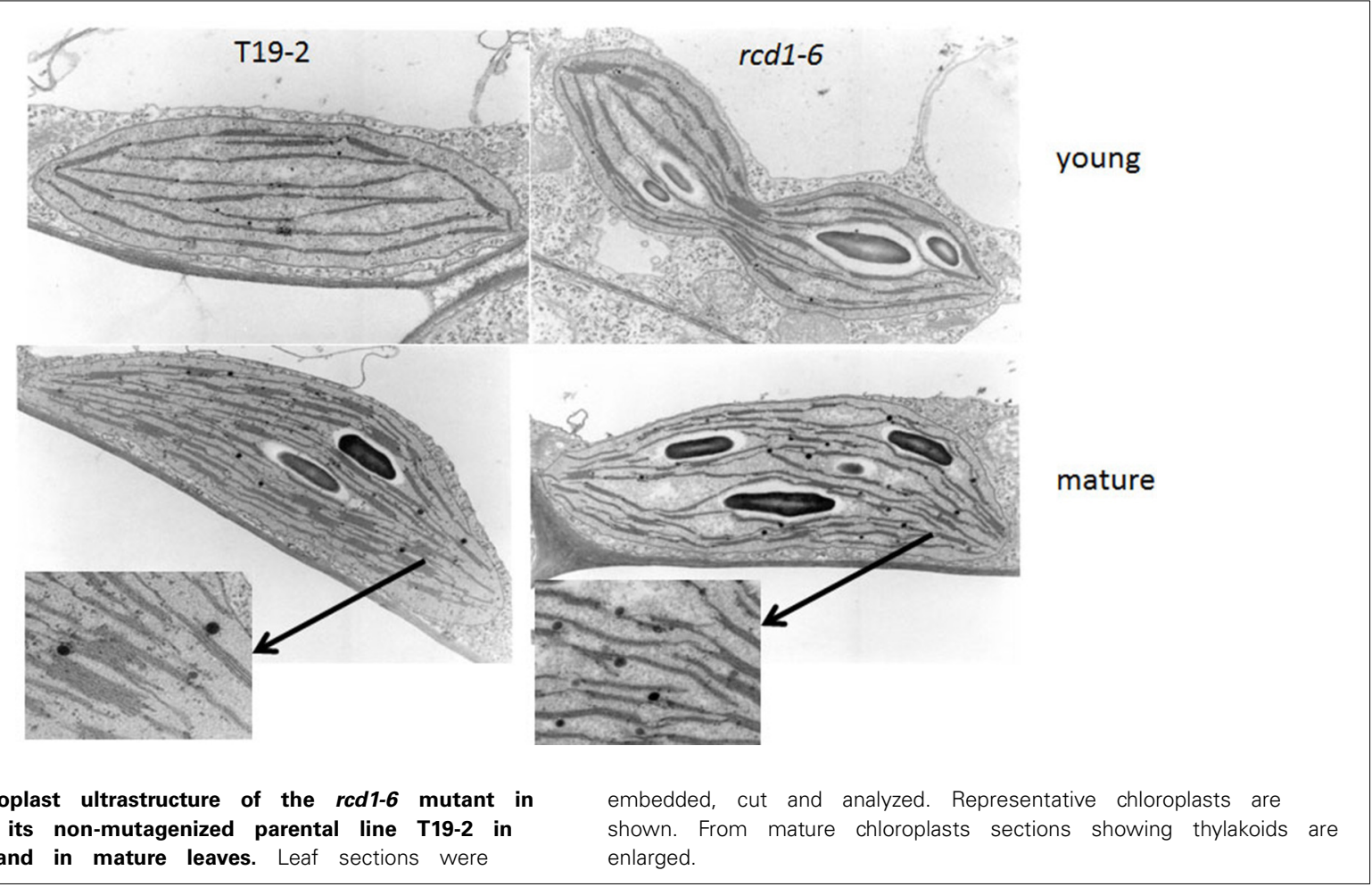

Rcd1-6 seedlings germinate and green normally (Heiber et al., 2007). Like in other $r c d 1$ alleles (Overmyer et al., 2005; Teotia and Lamb, 2009; Zhu et al., 2013), rcd1 characteristic phenotypes develop in the rosette stage with maturation of the first true leaves. $r c d 1-6$ shows stunted growth, formation of aerial rosettes, decreased number of flowers and leaf damage as reported before for $r c d 1-3$ (Teotia and Lamb, 2009). Starting at the leaf rims, chlorosis and necrosis takes place. The leaves get serrated and turn yellow (Figures 1B, 2B). In addition, cells partially collapse within the mesophyll layer, which can be observed as clefts on the abaxial site of mature leaves (Figure 3B).

\section{LESION FORMATION RESULTS FROM INSUFFICIENT CHLOROPLAST ANTIOXIDANT PROTECTION}

Lesion formation and hypersensitive responses correlate with ROS accumulation in rcdl-mutants (Overmyer et al., 2000; Zhu et al., 2013), which activates apoptotic processes (Foyer and Noctor, 2005; Baxter et al., 2014). In plants, programmed cell death is mainly triggered by chloroplasts in a combined action of photooxidative ROS production and signals correlating with a more reduced plastoquinone pool (Samuilov et al., 2003). RIMB1 was described as a major regulator in induction of the chloroplast antioxidant system (Heiber et al., 2007). Mapping of rimb1 to the $r c d 1$ locus (Figure 1) linked two independently created lines of redox signaling analysis and provides novel insights into the function of RCD1:

In wildtype plants, the genes for chloroplast antioxidant enzymes are quickly and strongly activated at the onset of leaf development (Pena-Ahumada et al., 2006). This induction is limited in rcd1-6 (Heiber et al., 2007). The redox buffering capacities are so low that in rcd1-6 (rimb1) even slight changes in the light intensity, such as exposure to just $100 \mu$ mol quanta $\mathrm{m}^{-2} \mathrm{~s}^{-1}$ more than the plants were acclimated to, transiently result in a $38 \%$ stronger reduction of the plastoquinone pool (1-qP; Figure 10) and the plants are very sensitive to variable environmental conditions (Suppl. 1).

Looking at much older plants (10-12 rosette leaves) than we routinely did (10 day old seedlings), Fujibe et al. (2004) showed higher ROS accumulation. Zhu et al. (2013) concluded that RCD1-typical induction of R-gene responses, activation of genes for extra-plastidic antioxidant enzymes and hypersensitive cell death result from the redox imbalances caused by insufficient antioxidant protection. Our work points out that the reason for insufficient antioxidant protection is caused early during plant development by limitations in the induction of genes for chloroplast antioxidant enzymes, while ROS-promoting greening and thylakoid development are not primarily affected.

One of the most puzzling results on RCD1 is that the $r c d 1$ 6 mutant was isolated for its limitation in activation of the genes of the chloroplast antioxidant system and is, like other rcd1 alleles (Ahlfors et al., 2004; Fujibe et al., 2004), more tolerant than its parental line to paraquat, which promotes photooxidative ROS production in chloroplasts (Mehler, 1951). In our opinion, paraquat tolerance of $r c d 1$ mutants is not linked in the first instance to the RCD1 function in the early activation of the chloroplast antioxidant system, but results from slower paraquat uptake due to differences in the epidermis structure, such as stress-induced stronger or denser cuticles upon stress (Dominguez et al., 2011) or the lower numbers of stomata (Figure 9). In this context it might be interesting to add 


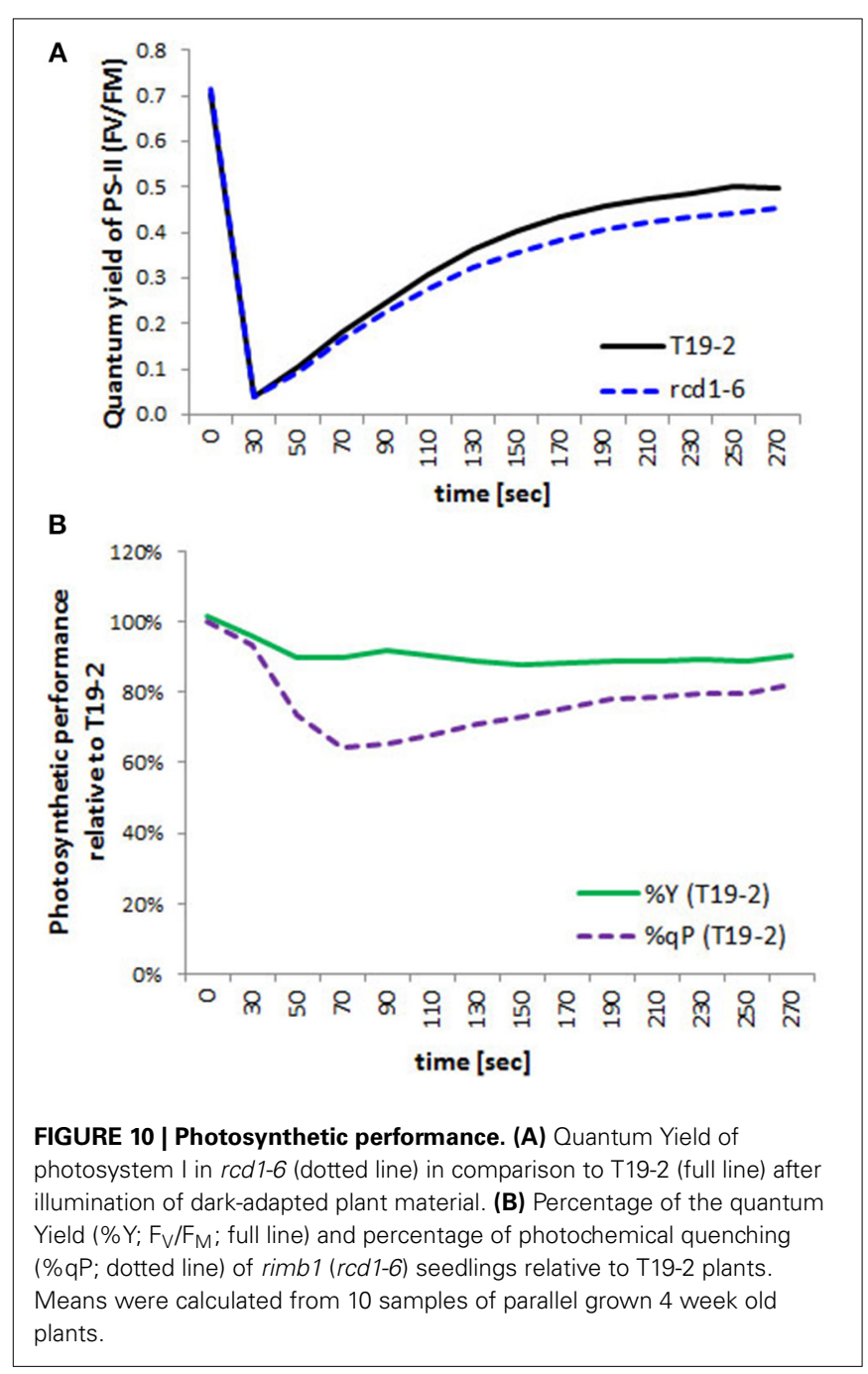

that RCD1 also interacts with the AP2-type transcription factor DREB2A, which mediates drought responses (Vainonen et al., 2012).

The antioxidant system is almost at its limits in young wildtype Arabidopsis while it has to cope with developmental activation of photosynthesis (Pena-Ahumada et al., 2006). Limitations in the synthesis of enzymatic and non-enzymatic antioxidants further strain the chloroplast redox poise control in the $r c d 1$-mutant (Heiber et al., 2007). As a consequence of insufficient protection, cells tend stronger to run into the cell death program (Figure 3B; Teotia and Lamb, 2011). During the time of these analyses, we moved twice our lab between universities. This gave us unintentionally the chance to see the mutant under different growth conditions. Comparison of plant populations grown over the time at various places, demonstrated that the extent of damage is conditional (Suppl. 1). Consistent with limitations in glutathione synthesis and the expression of genes for chloroplast antioxidant enzymes (Heiber et al., 2007) rcd1 phenotypes are pronounced in a genetic background with low biosynthesis of the antioxidant ascorbate (Zhu et al., 2013). The lack of RCD1 caused also stronger phenotypes, when the mutants were exposed to ozone (Overmyer et al., 2005) or UV-B (Fujibe et al., 2004), or crossed with mutants limited in other stress response pathways, such as snc1 (Zhu et al., 2013) and ein2 (Overmyer et al., 2005).

\section{THE RCD1 EFFECT IS AGE DEPENDENT}

Overmyer et al. (2000) reported low expression of chloroplast Csd2 for $r c d 1$-1, like we did for young $r c d 1-6$ (Heiber et al., 2007). The transcript level of the same gene was increased in the report of Fujibe et al. (2004) on rcd1-2. Between these experiments, the age of the plants and the growth conditions varied. Comparison of 2-6 week old plants demonstrated that the positive RCD1 effect on $2 C P A, s A P x$, and $C s d 2$ expression can be inverted during development (Figure 8 in comparison to Heiber et al., 2007; Figure 9). RCD1 supports activation of the chloroplast antioxidant system specifically in young tissues. Besides RCD1dependent regulation, additional stress-dependent activation can take place. As shown previously, for example higher light intensity (Heiber et al., 2007) and $23^{\circ} \mathrm{C}$ growth temperature (Fujibe et al., 2004), severe stress can induce expression of genes for chloroplast antioxidant enzymes in $r c d 1$ mutants in an RCD1-independent manner.

RCD1 and Rap2.4a regulation control preferentially genes for chloroplast antioxidant enzymes (Heiber et al., 2007; Shaikhali et al., 2008; Figure 7). They do not control the expression of genes for light-harvesting complex proteins or the also nuclear encoded small subunit of ribulose-1,5-bisphosphate carboxylase/oxygenase, which are also massively induced in young mesophyll cells in response to chloroplast signals (summarized in: Pfannschmidt, 2003; Baier and Dietz, 2005). Consistently, chlorophyll biosynthesis (Heiber et al., 2007) or early development of the chloroplast ultrastructure, such as thylakoid formation and initiation of grana stacking (Figure 9), take place similar as in wildtype plants.

\section{POSITION OF RCD1 WITHIN THE SIGNALING NETWORK}

RCD1 regulates, like Rap2.4a (Shaikhali et al., 2008), sAPX, $t A P x$, and Csd2 expression (Heiber et al., 2007). Like Rap2.4a knockout lines (Shaikhali et al., 2008), rcd1-mutants can grow almost symptom-free (Overmyer et al., 2005; Heiber et al., 2007). Chlorosis, lesions and early leaf senescence preferentially develop in long-days or under fluctuating light conditions (Heiber et al., 2007; Shaikhali et al., 2008) (Suppl. 1). The physical interaction (Figure 4), the target overlap and the similar symptoms of knock-out lines (Heiber et al., 2007; Shaikhali et al., 2008; here) show that RCD1 functions as upstream-regulator in the Rap2.4a-mediated redox protection.

Positive interaction in yeast-two-hybrid tests (Figure 4) indicates that RCD1 acts as a direct upstream-regulators of Rap2.4a. Similar to the motif predicted by Vainonen et al. (2012) from the comparison of positive and negative interactions of RCD1 with AP2-type-transcription factors (FDXXELLXXLN) Rap2.4a has a FDXXEeaXXLa motif containing the essential FD-element and the $\mathrm{E}$ of the also experimentally proven ELL-motif (Vainonen et al., 2012).

Co-existence of RCD1 and Rap2.4a is essential for ascorbateinduced redox regulation of 2CPA expression (Figure 6), while 


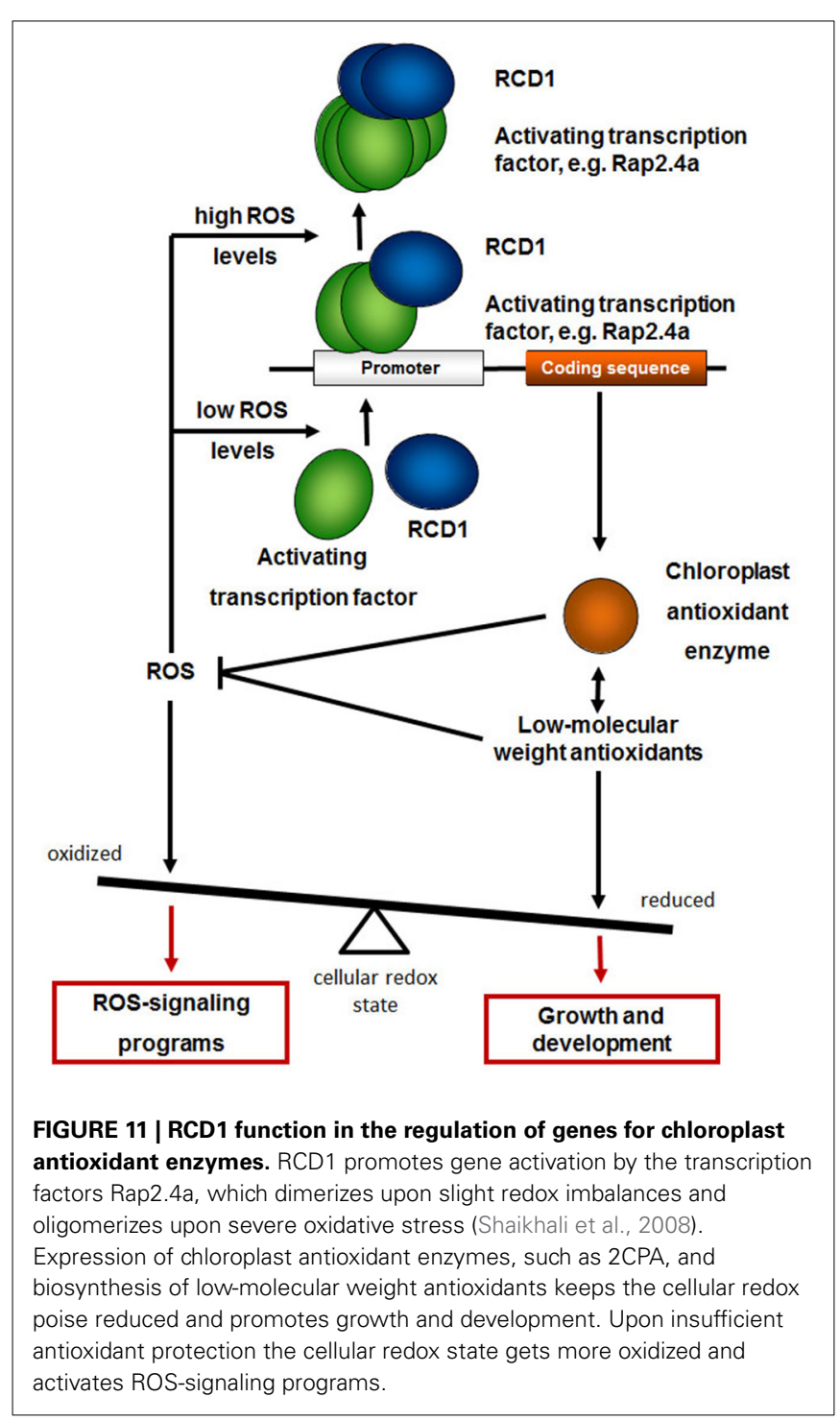

the interaction of Rap2.4a and RCD1 only slightly responds to oxidation and is insensitive to reduction in the yeast-two-hybrid assay (Figure 5). Regulation of the genes for chloroplast antioxidant enzymes takes place via a signal transduction pathway regulating Rap2.4a activity (Shaikhali et al., 2008; Shaikhali and Baier, 2010). The here presented data let assume that RCD1 only potentiates the Rap2.4a effect.

Rap2.4a availability supports $R C D 1$ expression (Figure 6) and RCD1 availability Rap2.4a expression (Figure 8). Truncated RCD1, which lacks the transcription factor binding site, is sufficient to increase the Rap2.4a transcript amount (Figure 8). Consequently, an auto-feedback loop depending on RCD1Rap 2.4 protein interaction can be excluded. Furthermore, $R C D 1$ overexpression does not overprotect, but gives a weak $r c d 1$ phenotype (Fujibe et al., 2006). We exclude direct feedback and suggest that Rap2.4a availability, which is essential for full expression of the genes for chloroplast antioxidant enzymes, is embedded in a transcription control network in which RCD1 masters the junctions.

\section{INTERPRETATION OF THE ROOT PHENOTYPE}

Besides cell death in leaves, $r c d 1$ mutants show defects in root development (Teotia and Lamb, 2009) (Figure 3A). RCD1 and Rap2.4a are both strongly expressed in roots (Ahlfors et al., 2004; Shaikhali et al., 2008), where they may trigger a root-specific regulatory circuitry. Based on the data we collected for $r c d 1-6$ ( rimb1) (Heiber et al., 2007 and here) we propose interpretation of the root defects as pleiotropic root meristemless 1 ( rml1)-like effect:

The $r m l 1$ mutant is deficient in $\gamma$-glutamyl-cysteine synthase (Vernoux et al., 2000), which catalyzes the first step of glutathione synthesis. Due to lack of glutathione, root meristem function is lost very early in development and the plants die before postembryonic shoot development is activated (Cheng et al., 1995). In $r c d 1-6$ (rimb1), the transcript levels of $\gamma$-glutamyl-cysteine synthase are only about half of the wildtype levels and the glutathione content is strongly decreased (Heiber et al., 2007). Due to also low enzymatic antioxidant support, the GSSG/GSH ratio is increased in rcd1-6 (rimb1) (Heiber et al., 2007). In plants, $\gamma$ glutamyl-cysteine synthesis takes place in chloroplasts (Wachter et al., 2005), where C- and $\mathrm{N}$-assimilation provide its educts. The limitations in activating the nuclear transcription of chloroplast $\gamma$-glutamyl-cysteine synthase gives $r c d 1-6$ a soft $r m l 1$ mutant phenotype by disturbing redox-dependent cell-cycle control and, consequently, postembryonic root development and shoot meristematic activities (Vernoux et al., 2000; Teotia and Lamb, 2011).

The here described $r c d 1-6$ mutant shows weaker root elongation and branching effects than the $r c d 1-3$ allele described by Teotia and Lamb (2009). Since we grew our plants in short-days, while Teotia and Lamb (2009) worked under more straining longday conditions $\left(16 \mathrm{~h}, 80 \mu \mathrm{mol}\right.$ quanta $\mathrm{m}^{-2} \mathrm{~s}^{-1} ; 8 \mathrm{~h}$ darkness) (Becker et al., 2006; Queval et al., 2011) the phenotype difference fits with the general pattern of phenotype penetrance variation in rcd1-6 (Suppl. 1).

\section{CONCLUSION}

RCD1 was shown to control disease responses, cell death and the meristem fate in a ROS-dependent manner (Cheng et al., 1995; Overmyer et al., 2005; Teotia and Lamb, 2011). RIMB1 was characterized as a major regulator in the activation of chloroplast antioxidant system in seedlings and in the early rosette stage (Heiber et al., 2007). Mapping of rimb1 to the rcd1 locus and confirming the $r c d 1$-phenotypes for rimb1 linked the induction of disease response pathways and cell death to limited activation of the chloroplast antioxidant system.

With respect of signal transduction, we showed that RCD1 can interact with the transcription factor Rap2.4a, which was previously identified to activate various genes for chloroplast antioxidant enzymes and to be essential for protecting cells from photooxidative stress (Shaikhali et al., 2008). The RCD1-Rap2.4a interaction in yeast was barely redox-responsive. Together with the impact of RCD1 on Rap2.4a expression, it indicates that RCD1 does not perform, but support redox-regulation.

In $r c d 1$ mutants, ROS-sensitive signaling cascades, such as induction of $A P x 2$ and $P R$ genes (Miller et al., 2008), are activated (Heiber et al., 2007). Hypersensitive responses and cell death programs are promoted in absence of abiotic and biotic stressors (Teotia and Lamb, 2011; Zhu et al., 2013; Baxter et al., 2014). 
During development, the RCD1-impact on the activation of the chloroplast antioxidant system precedes the stress symptoms. In summary, we conclude that RCD1 protects plants cells from activation of ROS-signaling cascades by supporting regulation of genes encoding chloroplast antioxidant enzymes and glutathione biosynthesis (Figure 11).

\section{ACCESSION NUMBERS}

Actin: At5g09810; Act-2: At3g18780; ApL3: At4g39210; Apx2: At3g09640, 2CPA: At3g11630, chlGR: At3g54660; Csd2: At2g 28190; Lhca2.1: At3g61470; Lhca5: At1g45474; Lhcb2.2: At2g 05070; Lhcb4.1: At5g01530; Rap2.4a: At1g36060; RCD1: At1g 32230; sAPx: At4g08390; SRO1: At2g35510; tAPx: At1g77490; ZAT10: At1g27730.

\section{AUTHOR CONTRIBUTIONS}

Isabelle Heiber started the mapping population, Heiko Hiltscher mapped the rimb1-mutation and performed the comparative habitus studies. Jehad Shaikhali carried out the yeast-two-hybrid analysis and the ascorbate experiment. Radoslaw Rudnik, Marina Mellenthin, and Isabelle Heiber performed PCR-based transcript abundance analyses. Radoslaw Rudnik and Margarete Baier did the allelism tests. Günter Schuster and Heiko Hiltscher did the SEM studies, Iuri Meirelles Duarte and Heiko Hiltscher the light microscopy and Uwe Kahmann the TEM comparison of chloroplasts. Margarete Baier coordinated and supervised the project, performed the chlorophyll-a fluorescence analysis and drafted the manuscript based on sections contributed by Heiko Hiltscher, Isabelle Heiber, Jehad Shaikhali, and Radoslaw Rudnik and method descriptions by Günter Schuster.

\section{ACKNOWLEDGMENTS}

We thank the DFG (Ba2011/2 and 4-3), the Freie Universität Berlin, the Heinrich-Heine-University Düsseldorf and Bielefeld University for support and, especially, the gardeners at our three universities for their help to optimize the growth conditions and to take care of the sensitive rimb1 mutant. Special thanks also to Ulrike Ellersiek and Elena Reifschneider for technical assistance and Dr. Christiane Hedtmann and Dr. Rainer Bode for critical reading and support during manuscript finalization.

\section{SUPPLEMENTARY MATERIAL}

The Supplementary Material for this article can be found online at: http://www.frontiersin.org/journal/10.3389/fpls.2014.00475/ abstract

\section{REFERENCES}

Ahlfors, R., Lang, S., Overmyer, K., Jaspers, P., Brosche, M., Tauriainen, A., et al. (2004). Arabidopsis RADICAL-INDUCED CELL DEATH1 belongs to the WWE protein-protein interaction domain protein family and modulates abscisic acid, ethylene, and methyl jasmonate responses. Plant Cell 16, 1925-1937. doi: 10.1105/tpc.021832

Armengaud, P., Zambaux, K., Hills, A., Sulpice, R., Pattison, R. J., Blatt, M. R., et al. (2009). EZ-Rhizo: integrated software for the fast and accurate measurement of root system architecture. Plant J. 57, 945-956. doi: 10.1111/j.1365313X.2008.03739.x

Arvidsson, S., Kwasniewski, M., Riano-Pachon, D. M., and Mueller-Roeber, B. (2008). QuantPrime - a flexible tool for reliable high-throughput primer design for quantitative PCR. BMC Bioinformatics 9:465. doi: 10.1186/1471-2105-9-465
Ausubel, F. M., Berndt, K. D., and Holmgren, A. (2001). Current Protocol in Molecular Biology. New York, NY: Wiley. doi: 10.1002/0471142727

Baier, M., and Dietz, K.-J. (1999). The costs and benefits of oxygen for photosynthesizing plant cells. Prog. Bot. 60, 282-314. doi: 10.1007/978-3-642-59940-8_11

Baier, M., and Dietz, K.-J. (2005). Chloroplasts as source and target of cellular redox regulation: a discussion of chloroplast-to-nucleus signals in context of plant physiology and evolution. J. Exp. Bot. 56, 1449-1462. doi: 10.1093/jxb/ eri161

Baier, M., Noctor, G., Foyer, C. H., and Dietz, K. J. (2000). Antisense suppression of 2-cysteine peroxiredoxin in Arabidopsis specifically enhances the activities and expression of enzymes associated with ascorbate metabolism but not glutathione metabolism. Plant Physiol. 124, 823-832. doi: 10.1104/pp.124.2.823

Baier, M., Ströher, E., and Dietz, K. J. (2004). The acceptor availability at photosystem I and ABA control nuclear expression of 2-Cys peroxiredoxin-A in Arabidopsis thaliana. Plant Cell Physiol. 45, 997-1006. doi: 10.1093/pcp/pch114

Baxter, A., Mittler, R., and Suzuki, N. (2014). ROS as key players in plant stress signalling. J. Exp. Bot. 65, 1229-1240. doi: 10.1093/jxb/ert375

Bechtold, U., Richard, O., Zamboni, A., Gapper, C., Geisler, M., Pogson, B., et al. (2008). Impact of chloroplastic- and extracellular-sourced ROS on high light-responsive gene expression in Arabidopsis. J. Exp. Bot. 59, 121-133. doi: 10.1093/jxb/erm 289

Becker, B., Holtgrefe, S., Jung, S., Wunrau, C., Kandlbinder, A., Baier, M., et al. (2006). Influence of the photoperiod on redox regulation and stress responses in Arabidopsis thaliana L. (Heynh.) plants under long- and short-day conditions Planta 224, 380-393. doi: 10.1007/s00425-006-0222-3

Belles-Boix, E., Babiychuk, E., Van Montagu, M., Inze, D., and Kushnir, S. (2000). CEO1, a new protein from Arabidopsis thaliana, protects yeast against oxidative damage. FEBS Lett. 482, 19-24. doi: 10.1016/S0014-5793(00)02016-0

Cheng, J.-C., Seeley, K. A., and Sung, Z. R. (1995). RML1 and RML2, Arabidopsis genes required for cell proliferation at the root tip. Plant Physiol. 107, 365-376. doi: 10.1104/pp.107.2.365

Dominguez, E., Heredia-Guerrero, J. A., and Heredia, A. (2011). The biophysical design of plant cuticles: an overview. New Phytol. 189, 938-949. doi: 10.1111/j.1469-8137.2010.03553.x

Foyer, C. H., Lelandais, M., and Kunert, K. J. (1994). Photooxidative stress in plants. Physiol. Plant. 92, 696-717. doi: 10.1111/j.1399-3054.1994.tb03042.x

Foyer, C. H., and Noctor, G. (2005). Redox homeostasis and antioxidant signaling: a metabolic interface between stress perception and physiological responses. Plant Cell 17, 1866-1875. doi: 10.1105/tpc.105.033589

Fujibe, T., Saji, H., Arakawa, K., Yabe, N., Takeuchi, Y., and Yamamoto, K. T. (2004). A methyl viologen-resistant mutant of Arabidopsis, which is allelic to ozone-sensitive $r c d 1$, is tolerant to supplemental ultraviolet-B irradiation. Plant Physiol. 134, 275-285. doi: 10.1104/pp.103.033480

Fujibe, T., Saji, H., Watahiki, M. K., and Yamamoto, K. T. (2006). Overexpression of the Radical-induced Cell Death 1 (Rcd1) Gene of Arabidopsis causes weak RCD1 phenotype with compromised oxidative-stress responses. Biosci. Biotechnol. Biochem. 70, 1827-1831.

Heiber, I., Ströher, E., Raatz, B., Busse, I., Kahmann, U., Bevan, M. W., et al. (2007). The redox imbalanced mutants of Arabidopsis differentiate signaling pathways for redox regulation of chloroplast antioxidant enzymes. Plant Physiol. 143, 1774-1788. doi: 10.1104/pp.106.093328

Horling, F., Lamkemeyer, P., König, J., Finkemeier, I., Kandlbinder, A., Baier, M., et al. (2003). Divergent light-, ascorbate-, and oxidative stress-dependent regulation of expression of the peroxiredoxin gene family in Arabidopsis. Plant Physiol. 131, 317-325. doi: 10.1104/pp.010017

Jander, G., Norris, S. R., Rounsley, S. D., Bush, D. F., Levin, I. M., and Last, R. L. (2002). Arabidopsis map-based cloning in the post-genome era. Plant Physiol 129, 440-450. doi: 10.1104/pp.003533

Jaspers, P., Blomster, T., Brosché, M., Salojärvi, J., Ahlfors, R., Vainonen, J. P., et al. (2009). Unequally redundant RCD1 and SRO1 mediate stress and developmental responses and interact with transcription factors. Plant J. 60, 268-279. doi: 10.1111/j.1365-313X.2009.03951.x

Jaspers, P., Brosche, M., Overmyer, K., and Kangasjärvi, J. (2010). The transcription factor interacting protein RCD1 contains a novel conserved domain. Plant Signal. Behav. 5, 78-80. doi: 10.4161/psb.5.1.10293

Juszczak, I., Rudnik, R., Pietzenuk, B., and Baier, M. (2012). Natural genetic variation in the expression regulation of the chloroplast antioxidant system among Arabidopsis thaliana accessions. Physiol. Plant. 146, 53-70. doi: 10.1111/j.13993054.2012.01602.x 
Kangasjärvi, S., Lepisto, A., Hannikainen, K., Piippo, M., Luomala, E. M., Aro, E. M., et al. (2008). Diverse roles for chloroplast stromal and thylakoid-bound ascorbate peroxidases in plant stress responses. Biochem. J. 412, 275-285. doi: 10.1042/BJ20080030

Karpinski, S., Escobar, C., Karpinska, B., Creissen, G., and Mullineaux, P. M. (1997). Photosynthetic electron transport regulates the expression of cytosolic ascorbate peroxidase genes in Arabidopsis excess light stress. Plant Cell 9, 627-640. doi: 10.1105/tpc.9.4.627

Katiyar-Agarwal, S., Zhu, J., Kim, K., Agarwal, M., Fu, X., Huang, A., et al. (2006). The plasma membrane $\mathrm{Na}+/ \mathrm{H}+$ antiporter SOS1 interacts with RCD1 and functions in oxidative stress tolerance in Arabidopsis. Proc. Natl. Acad. Sci. U.S.A. 103, 18816-18821. doi: 10.1073/pnas.0604711103

König, J., Baier, M., Horling, F., Kahmann, U., Harris, G., Schürmann, P., et al. (2002). The plant-specific function of 2-Cys peroxiredoxin-mediated detoxification of peroxides in the redox-hierarchy of photosynthetic electron flux. Proc. Natl. Acad. Sci. U.S.A. 99, 5738-5743. doi: 10.1073/pnas.072644999

Lee, J., Godon, C., Lagniel, G., Spector, D., Garin, J., Labarre, J., et al. (1999). Yap1 and Skn1 control specialized oxidative stress response regulons in yeast. J. Biol. Chem. 274, 16040-16046. doi: 10.1074/jbc.274.23.16040

Li, B., and Fields, S. (1993). Identification of mutations in p53 that affect its binding to SV40 large T antigen by using the yeast-two-hybrid system. FASEB J. 7, 957-963.

Li, L., Elledge, S. J., Peterson, C. A., Bales, E. S., and Legerski, R. J. (1994). Specific association between the human Dna-Repair proteins Xpa and Erccl. Proc. Natl. Acad. Sci. U.S.A. 91, 5012-5016. doi: 10.1073/pnas.91.11.5012

Mehler, A. H. (1951). Studies on reactions of illuminated chloroplasts. II. Stimulation and inhibition of reactions with molecular oxygen. Arch. Biochem. Biophys. 33, 339-351. doi: 10.1016/0003-9861(51)90012-4

Miller, G., Shulaev, V., and Mittler, R. (2008). Reactive oxygen signaling and abiotic stress. Physiol. Plant. 133, 481-489. doi: 10.1111/j.1399-3054.2008. 01090.x

Mittler, R., Kim, Y., Song, L. H., Coutu, J., Coutu, A., Ciftci-Yilmaz, S., et al. (2006). Gain- and loss-of-function mutations in Zat10 enhance the tolerance of plants to abiotic stress. Febs Lett. 580, 6537-6542. doi: 10.1016/j.febslet.2006. 11.002

Overmyer, K., Brosche, M., Pellinen, R., Kuittinen, T., Tuominen, H., Ahlfors, R., et al. (2005). Ozone-induced programmed cell death in the Arabidopsis radical-induced cell death1 mutant. Plant Physiol. 137, 1092-1104. doi: 10.1104/pp.104.055681

Overmyer, L., Tuominen, H., Kettunen, R., Betz, C., Langebartels, C., Sandermann, H., et al. (2000). Ozone-sensitive Arabidopsis rcd1 mutant reveals opposite roles for ethylene and jasmonate signaling pathways in regulating superoxidedependent cell death. Plant Cell 12, 1849-1862. doi: 10.1105/tpc.12.10.1849

Pena-Ahumada, A., Kahmann, U., Dietz, K. J., and Baier, M. (2006). Regulation of peroxiredoxin expression versus expression of Halliwell-Asada-Cycle enzymes during early seedling development of Arabidopsis thaliana. Photosynth. Res. 89, 99-112. doi: 10.1007/s11120-006-9087-3

Pfannschmidt, T. (2003). Chloroplast redox signals: how photosynthesis controls its own genes. Trends Plant Sci. 8, 33-41. doi: 10.1016/S1360-1385(02)00005-5

Queval, G., Jaillard, D., Zechmann, B., and Noctor, G. (2011). Increased intracellular $\mathrm{H}_{2} \mathrm{O}_{2}$ availability preferentially drives glutathione accumulation in vacuoles and chloroplasts. Plant Cell Environ. 34, 21-32. doi: 10.1111/j.13653040.2010.02222.x

Rossel, J. B., Wilson, P. B., Hussain, D., Woo, N. S., Gordon, M. J., Mewett, O. P., et al. (2007). Systemic and intracellular responses to photooxidative stress in Arabidopsis. Plant Cell 19, 4091-4110. doi: 10.1105/tpc.106.045898

Samuilov, V. D., Lagunova, E. M., Dzyubinskaya, E. V., Izyumov, D. S., Kiselevsky, D. B., and Makarova, Y. V. (2002). Involvement of chloroplasts in the programmed cell death of plant cells. Biochemistry 67, 627-634. doi: 10.1023/A: 1016138003183

Samuilov, V. D., Lagunova, E. M., Kiselevsky, D. B., Dzyubinskaya, E. V., Makarova, Y. V., and Gusev, M. V. (2003). Participation of chloroplasts in plant apoptosis. Biosci. Rep. 23, 103-117. doi: 10.1023/A:1025576307912
Schneider, S., Buchert, M., and Hovens, C. M. (1996). An in vitro assay of betagalactosidase from yeast. Biotechniques 20, 960-962.

Schreiber, U., and Bilger, W. (1993). Progress in chlorophyll fluorescence research: major developments during the past years in retrospect. Prog. Bot. 54, 151-173.

Shaikhali, J., and Baier, M. (2010). Ascorbate regulation of 2-Cys peroxiredoxinA promoter activity is light-dependent. J. Plant Physiol. 167, 461-467. doi: 10.1016/j.jplph.2009.10.021

Shaikhali, J., Heiber, I., Seidel, T., Ströher, E., Hiltscher, H., Birkmann, S., et al. (2008). The redox-sensitive transcription factor Rap2.4a controls nuclear expression of 2-Cys peroxiredoxin A and other chloroplast antioxidant enzymes. BMC Plant Biol. 8:48. doi: 10.1186/1471-2229-8-48

Sheffield, J. B. (2007). ImageJ, a useful tool for biological image processing and analysis. Microsc. Microanal. 13, 200-201. doi: 10.1017/S1431927607076611

Teotia, S., and Lamb, R. S. (2009). The paralogous genes RADICAL-INDUCED CELL DEATH1 and SIMILAR TO RCD ONE1 have partially redundant functions during Arabidopsis development. Plant Physiol. 151, 180-198. doi: 10.1104/pp.109.142786

Teotia, S., and Lamb, R. S. (2011). RCD1 and SRO1 are necessary to maintain meristematic fate in Arabidopsis thaliana. J. Exp. Bot. 62, 1271-1284. doi: $10.1093 /$ jxb/erq363

Vainonen, J. P., Jaspers, P., Wrzaczek, M., Lamminmaki, A., Reddy, R. A., Vaahtera, L., et al. (2012). RCD1-DREB2A interaction in leaf senescence and stress responses in Arabidopsis thaliana. Biochem. J. 442, 573-581. doi: 10.1042/BJ20111739

Vernoux, T., Wilson, R. C., Seeley, K. A., Reichheld, J. P., Muroy, S., Brown, S., et al. (2000). The ROOT MERISTEMLESS1/CADMIUM SENSITIVE2 gene defines a glutathione-dependent pathway involved in initiation and maintenance of cell division during postembryonic root development. Plant Cell 12, 97-110. doi: 10.1105/tpc.12.1.97

Wachter, A., Wolf, S., Steininger, H., Bogs, J., and Rausch, T. (2005). Differential targeting of GSH1 and GSH2 is achieved by multiple transcription initiation: implications for the compartmentation of glutathione biosynthesis in the Brassicaceae. Plant J. 41, 15-30. doi: 10.1111/j.1365-313X.2004.02269.x

Wood, Z. A., Poole, L. B., and Karplus, P. A. (2003). Peroxiredoxin evolution and the regulation of hydrogen peroxide signaling. Science 300, 650-653. doi: 10.1126/science. 1080405

Zapata, J. M., Guera, A., Esteban-Carrasco, A., Martin, M., and Sabater, B. (2005). Chloroplasts regulate leaf senescence: delayed senescence in transgenic ndhFdefective tobacco. Cell Death Differ. 12, 1277-1284. doi: 10.1038/sj.cdd.4401657

Zhu, Y., Du, B., Qian, J., Zou, B., and Hua, J. (2013). Disease resistance gene-induced growth inhibition is enhanced by rcdl independent of defense activation in Arabidopsis. Plant Physiol. 161, 2005-2013. doi: $10.1104 /$ pp.112.213363

Conflict of Interest Statement: The authors declare that the research was conducted in the absence of any commercial or financial relationships that could be construed as a potential conflict of interest.

Received: 17 May 2014; accepted: 28 August 2014; published online: 23 September 2014.

Citation: Hiltscher H, Rudnik R, Shaikhali J, Heiber I, Mellenthin M, Meirelles Duarte I, Schuster G, Kahmann U and Baier M (2014) The radical induced cell death protein 1 (RCD1) supports transcriptional activation of genes for chloroplast antioxidant enzymes. Front. Plant Sci. 5:475. doi: 10.3389/fpls.2014.00475

This article was submitted to Plant Physiology, a section of the journal Frontiers in Plant Science.

Copyright (C) 2014 Hiltscher, Rudnik, Shaikhali, Heiber, Mellenthin, Meirelles Duarte, Schuster, Kahmann and Baier. This is an open-access article distributed under the terms of the Creative Commons Attribution License (CC BY). The use, distribution or reproduction in other forums is permitted, provided the original author(s) or licensor are credited and that the original publication in this journal is cited, in accordance with accepted academic practice. No use, distribution or reproduction is permitted which does not comply with these terms. 